Reprod. Nutr. Dévelop., 1980, 20 (5 B), 1563-1614.

\title{
Bases physiologiques du comportement alimentaire chez les ruminants
}

\author{
par F. GALLOUIN, M. FOCANT *
}

\author{
Institut national agronomique Paris-Grignon \\ 16, rue Claude-Bernard, 75231 Paris cedex 05 \\ * Université catholique de Louvain \\ Laboratoire de Biochimie de la Nutrifion, \\ place Croix-du-Sud, 3, B-1348 Louvain la Neuve, Belgique.
}

\section{Summary. The physiological bases of feeding behavior in ruminants.}

According to Le Magnen, feeding behavior may be defined as « the overall actions of an animal by which it ingests suitable food for satisfying its organic needs and refuses substances which are not food or are toxic $\gg$.

This definition thus supposes that the animal has learned to recognize edible substances or that innate reflexes, of which we are unaware, are involved. Feeding behavior is initiated by a need to eat (hunger), and it ceases when the ruminant is satiated. Two antagonistic processes are thus implicated : the first initiates the behavior, and the second stops it. Most of the work done on the regulation of feeding behavior has concerned satiety mechanisms. In fact, it is difficult to quantify the need of an animal to eat, while satiety is generally easy to observe.

As all other mammals, ruminants have a milk diet during the neonatal period. But if the young animal has a free choice, it soon prefers grass which has a different chemical composition than milk. This change in food preference results in an overall transformation of the gastric compartments into a system adapted to cellulose digestion. This modification occurs in the pre-weaning period and is expressed by the appearance of a special behavior, that of rumination or merycism. In these compartments, a flora and a fauna develop and live on the food the animal eats. Cellulose degradation products, i.e. volatile fatty acids (VFA) such as acetic, propionic or butyric acids, form and are used by the host as a source of energy. There is true symbiosis between the rumen micropopulation and the ruminant. The animal's characteristic feeding behavior is a result of its cumbersome diet, the presence of gastric compartments, micropopulation metabolites and of rumination.

The feeding behavior of ruminants should be studied on the pasture. According to Ruckebusch, the food intake, the total duration of rumination and the rest period each last $8 \mathrm{hrs}$ in cattle.

The meals, alternating with periods of rumination, are eaten mainly during the day; their relative length varies with grass quality.

Domestic ruminants eat 6 to 14 meals per day separated by rumination periods. The total duration of rumination depends on the length of the grass; it may drop to $\mathbf{4 5}$ min per day if the ration is ground.

The animal is satiated when the gastric compartments have been filled to a certain level. However, when the same diet is ground, the same amount is ingested. Thus, other factors, such as oropharyngeal sensations or metabolic and nervous factors related to the digestion of the meal, are responsible for shori-term satiety in ruminants. As intestinal transit rate, gastric activity affects food intake. These transits themselves depend on the state of vigilance. 
Satiety is a result of the absorption of the products of digestion through the rumen or the intestine. The volatile fatty acids produced inhibit food intake and rumination by acting either on specific receptors or by changing the transit.

Glycemia, blood volatile fatty acids and amino-acidemia do not seem to play a direct role in short-term satiety. Moreover, Forbes believes that no experiment has yet shown the exact role of digestive hormones in the control of satiety.

The size of the meals may vary in relation to the fattening state of the animal. The daily energy ingested decreases as the animal gains weight. Attempts have been made to explain this process as affected by free fatty acids, prostaglandins, insulin, growth hormone, sex hormones, glucocorticoids and temperature. In fact, all these factors have a metabolic effect on food intake and may cause some pathological states.

Psychological factors also play a role in modulating the satiety and hunger « centers ». This research on ruminants has only commenced but already promises some interesting practical applications.

\section{Sommaire.}

1. - Introduction.

2. - Les structures impliquées dans la réalisation du comportement alimentaire.

2.1. - Le tractus digestif.

2.2. - Rôles du système nerveux central dans la régulation de la prise alimentaire.

3. - Régulation du comportement alimentaire.

3.1. - Rôle de la réplétion du réticulo-rumen.

3.2. - Contrôle humoral de la prise alimentaire.

3.3. - Rôle des hormones digestives.

3.4. - Rôle d'autres facteurs endocriniens.

4. - Conclusion.

\section{1. - Introduction.}

Le comportement alimentaire est la première des régulations métaboliques car il permet le contrôle des entrées des nutriments dans l'organisme.

L'étude du comportement alimentaire peut être abordée de manières bien différentes. L'éthologiste observera les animaux dans leur milieu naturel et évitera le plus possible de les perturber. Le zootechnicien cherchera à connaître le régime alimentaire le mieux accepté par l'animal tout en assurant le maximum de performance en vue d'une production lactée ou de viande. Le physiologiste cherchera le déterminisme, c'est-à-dire le comment du comportement. C'est sous cet angle là que nous aborderons l'étude du comportement alimentaire des ruminants.

Le Magnen définit le comportement alimentaire comme «l'ensemble des actes de l'animal par lequel il ingère des aliments propres à satisfaire ses besoins organiques ef refuse les susbtances non alimentaires ou toxiques ». Cette définition, très généralisable à l'ensemble des mammifères et même du règne animal, appelle un certain nombre de commentaires. L'《 ensemble des actes » est très difficile à délimiter. La quête de nourriture, sa sélection ou choix, sa capture, sa mastication... constituent une partie de ces actes. 
La faim est la perception de l'état de besoin organique lorsque le ruminant ne s'est pas alimenté depuis un certain temps. Elle correspond, sans doute, pour lui, à un état de malaise et s'accompagne d'un désir vif et conscient de nourriture. La faim représente donc pour l'organisme un mécanisme de défense curatif. Il est très difficile de mesurer cette faim chez l'animal. Par contre, on pourra a posteriori, l'évaluer quand l'animal aura ingéré un repas plus ou moins copieux.

L'appétit est considéré classiquement comme une sensation agréable, une forme atténuée de la faim. En fait, on peut considérer comme phénomène d'appétit, toute consommation alimentaire qui, par sa valeur quantitative ou qualitative, traduit une anticipation par l'animal, au cours de l'exécution de sa prise orale, à la fois des besoins à couvrir et des effets métaboliques ultérieurs des aliments. En d'autres termes, l'animal adapte à un besoin latent qui ne s'est pas encore manifesté, une ingestion dont la composition et l'importance ne sont pas décelables directement par les capacités sensorielles de l'animal. Il s'agit là d'un remarquable exemple de mécanisme de défense préventif ; c'est un phénomène acquis résultant d'un apprentissage basé sur des expériences répétées.

Lors de ces expériences de choix alimentaire, limitées par la variété des espèces végétales environnantes, le ruminant « classe » les aliments selon ses préférences. La « palatabilité absolve » de l'aliment (Le Magnen) est la cote donnée par l'animal au début d'un repas et en fonction d'un degré plus ou moins intense de la faim. A la fin du repas, cette cote baisse progressivement et on peut donc parler à ce moment, de palatabilité relative de l'aliment. Le ruminant est apparemment rassasié, mais si on lui propose un autre régime (orge à la place du foin, ou betterave au lieu d'orge), il recommence à ingérer. La palatabilité du foin étaił devenue nulle, celle de l'orge et de la betterave était encore élevée.

La satiéfé est comme la faim, la perception d'un état interne : c'est un état euphorique apparaissant après une ingestion capable en général de satisfaire les besoins organiques. Le terme satiété sous-entend un état de réplétion satisfaisant (satis est = c'est assez) qu'il y a lieu de ne pas confondre avec le « koros » des grecs qui est assimilable à l'écœurement. La satiété est encore un état d'anticipation : lorsque l'animal s'arrête de manger, les besoins ou déficits organiques ne sont pas encore couverts puisque la digestion est à peine commencée et que de ce fait, les nutriments n'ont pas encore pénétré dans l'organisme. On peut donc considérer la satiété comme un phénomène d'alarme ou de défense préventif empêchant l'animal d'ingérer des quantités d'aliments dépassant ses possibilités d'utilisation digestive et métabolique.

Ces quelques définitions (Le Bars et Gallouin, 1972) permettent de penser que l'organisme animal est capable d'établir une relation entre l'effet sensoriel des aliments, qui se produit essentiellement au nivequ buccal et gastrique, et leurs effets métaboliques, énergétiques ef qualitatifs qui se manifestent principalement dans l'organisme même. L'appétit pour un aliment est basé surtout sur une analyse visuelle et, chez les animaux domestiques surtout, sur l'odeur et le goût (perception buccale). L'appétit esi limité du fait de l'apparition de la satiété, par une perception du volume ingéré au cours même du repas (perception buccale et gastrique). Cet appétit est cependant, quantitativement et qualitativement, fonction des propriétés nutritionnelles de l'aliment ef des besoins métaboliques à couvrir, qui varient d'ailleurs fortement en fonction de l'éłat physiologique imposé par les productions de l'animal. 
Un problème physiologique se pose donc : comment le besoin organique métabolique, quantitatif et qualitatif d'aliments, s'accompagne-t-il d'un comportement se traduisant par la découverte, la sélection et l'ingestion en quantités appropriées des aliments capables de satisfaire ces besoins et de supprimer les perturbations organiques qu'ils engendraient.

Nous n'aborderons pas, dans cette étude, les problèmes liés à la régulation du métabolisme de l'eau et des électrolytes, c'est-à-dire le déłerminisme de la soif. Toutefois, nous avons conscience que l'eau est un véritable aliment et que son ingestion conditionne en grande partie la prise des aliments énergétiques.

Dans cette étude nous envisagerons tout d'abord les problèmes posés par le comportement alimentaire du jeune ruminant. Puis nous essaierons de décrire le comportement alimentaire de quelques ruminants adultes. Nous aborderons ensuite l'étude des structures du système nerveux central qui contrôlent le déclenchement et l'arrêt des réponses alimentaires. Une intervention expérimentale directe sur ces structures nerveuses détermine des modifications très rapides, souvent presque immédiates, de la consommation alimentaire quantitative et qualitative, quelles que soient les conditions métaboliques de l'animal. Puis, nous envisagerons les problèmes liés à la régulation à court terme de la prise alimentaire en insistant particulièrement sur les facteurs humoraux et nerveux qui informent les centres nerveux des besoins de l'organisme. En l'état actuel de nos connaissances, il est extrêmement difficile de préciser quel est ou quels sont les facteurs métaboliques ou nerveux qui agissent de façon prépondérante sur la faim ou sur la satiété. Les ruminants présentent par rapport aux autres mammifères un certain nombre de particularités digestives et métaboliques qui ont orienté les recherches de ces vingt dernières années. II nous semble donc opportun de faire un bref rappel d'anatomie et de physiologie digestive des ruminants qui nous permettra de poser les problèmes avec plus de précision.

\section{2. - Les structures impliquées dans la réalisation du comportement ali- mentaire.}

\section{1. - Le tractus digestif.}

Le sous-ordre des ruminants appartient au super-ordre des ongulés, infraclasse des Euthéria, sous-classe des Theria, classe des Mammifères (Grassé, 1955). Les familles ayant des représentants dans la faune actuelle peuvent être groupés en ruminants digitigrades et ruminants onguligrades. Les ruminants digitigrades ne sont représentés que par la famille des Camelidae comprenant le chameau, le dromadaire, le lama, la vigogne, l'alpaca. Les ruminants onguligrades sont beaucoup mieux représentés. Ils sont classés en 6 familles qui sont les Tragulidae, Maschidae, Cervidae, Antilocapridae, Bovidae, Giraffidae. Les espèces dont le comportement sera évoqué dans cette étude ont été choisies, en raison du nombre considérable de travaux qui leur ont été consacrés dans la sous-famille des Bovinae, des Ovinae et des Caprinae.

En règle générale, les ruminants possèdent une dentition de type sélénodonte (dents dont la surface ressemble à un croissant de lune) très adaptée à la mastication de l'herbe. Ils sont caractérisés par la présence d'un estomac divisé en quatre sacs d'inégale grandeur. Le premier sac, la panse (rumen, ingluvium) est le plus volumineux, il 
occupe chez les bovins pratiquement la moitié gauche de la cavité abdominale et présente souvent des poches accessoires ; il est ouvert largement en avant par le col de la panse (ou orifice rumino-réticulaire : ouverfure elliptique de $18 \mathrm{~cm} \times 13 \mathrm{~cm}$ ) sur le deuxième réservoir ou réseau (bonnet, réticulum). Le réseau est en relation avec le troisième réservoir ou feuillet (psautier, omasum, livret, psalterium) par un étroit orifice qui ne laisse transiter que des particules alimentaires de taille réduite, en effet, cet orifice réticulo-omasal mesure chez la vache $2,5 \mathrm{~cm} \times 1,5 \mathrm{~cm}$. Le fevillet est de forme allongée et présente à l'intérieur une série de plis de la muqueuse orientés suivant sa longueur et disposés comme les feuilles d'un livre. Le rôle de ce réservoir est de réabsorber l'eau ef les électrolytes contenus dans les aliments (Brugère, 1969). Le feuillet débouche par l'orifice omaso-abomasal dans l'abomasum ou caillette qui est l'analogue de l'estomac d'un monogastrique comme le porc ou l'homme.

Cet ensemble de poches évolue après la naissance du ruminant. Chez le jeune ruminant, le lait ne transite pas normalement par le rumen ef le réseau, car il existe un dispositif particulier, la gouttière œsophagienne, qui fait communiquer directement l'œsophage avec le feuillet. La gouttière œsophagienne est constituée d'un demi-tube qui peut se transformer en un conduit parfait par rapprochement de ses deux lèvres. De ce fait, le lait ne tombe pas dans le sac réticulo-ruminal qui est alors peu développé. Au sevrage, ce sac deviendra extrêmement volumineux ef contiendra l'herbe que le ruminant ingère. La gouttière œsophagienne ne fonctionnera plus de la même manière que chez le jeune sauf en cas de déshydratation grave de l'animal : dans ce cas, l'eau de boisson arrivera directement dans le feuillet et la caillette permettant une restauration rapide du déficit hydrique.

Cette modification des réservoirs gastriques en fonction du régime alimentaire a des répercussions au niveau du comportement alimentaire. Nous voyons donc que le jeune, comme tous les autres mammifères, en alimentation lactée, peut être considéré comme un monogastrique. Il en a d'ailleurs le même comportement alimentaire, mais il se modifiera considérablement quand l'alimentation aura changé au sevrage. Toutefois, on peut imaginer que le ruminant garde encore une régulation de sa prise alimentaire voisine de celle d'un monogastrique. Cette manière d'envisager le problème est d'ailleurs en concordance avec les réalités expérimentales: il y a beaucoup de points communs dans la régulation de la prise alimentaire chez les monogastriques ef les ruminants. Il existe aussi de grandes différences liées à la physiologie digestive des ruminants, elle-même en rapport avec leur anatomie.

Les deux premiers pré-estomacs (sac réticulo-ruminal) chez l'adulte ont un rôle de réservoir dans lequel s'accumule et séjourne l'herbe. Le sac réticulo-ruminal contient après les repas, de 70 à 75 p. 100 de la matière sèche du tube digestif qui sera refenue à ce niveau de 30 à $70 \mathrm{~h}$ en moyenne.

Les éléments grossiers de la ration ne pourront pas transiter par le sphincter du feuillet, ils seront préalablement réduits grâce au mécanisme de rumination ou mérycisme ou comportement mérycique. La rumination fait partie intégrante du comportement alimentaire. L'acte de la rumination consiste en la régurgitation d'un bol alimentaire calibré prélevé dans le réseau atteignant la cavité buccale grâce à une onde antipéristaltique de l'œsophage. Les liquides contenus dans le bol sont alors exprimés et immédiatement déglutis. Les aliments sont ensuite mastiqués et insalivés abondam- 
ment, puis de nouveau déglutis. Après une période de repos de quelques secondes, un nouveau bol est régurgité. Bost et Ruckebusch (1960) ont démontré que la seule condition nécessaire à la rumination était l'atteinte du cardia par le niveau des ingesta. Le mérycisme a été décrit chez l'homme.

Les zones sensibles permettant le déclenchement des phénomènes moteurs de la rumination sont à rechercher au niveau même des estomacs. Cet aspect sera développé dans un chapitre ultérieur. Parmi les premiers travaux concernant la régulation humorale de la rumination, citons ceux de Le Bars, Nitescu et Simonnet (1953) qui constatent que l'hypoglycémie provoquée par administration d'insuline est le facteur excitant la motricité. Selon Bost $(1958 a, b)$, le centre bulbaire de la rumination reçoit en permanence des excitations rythmiques provenant du centre moteur des pré-estomacs. Dussardier a d'ailleurs démontré en 1960 que la motricité gastrique dépendait de la mise en jeu d'un arc réflexe dont la voie sensitive est représentée par le pneumogastrique. II est possible selon Iggo (1951) et Titchen (1953) d'obtenir des contractions réflexes du réseau par la stimulation vagale. Les centres nerveux sont donc situés au niveau bulbaire, la voie motrice descendante est représentée par les nerfs extrinsèques, y compris les pneumogastriques. Toutefois, les plexus intrapariétaux jouent le rôle déterminant de cette motricité.

Une autre particularité anatomique fondamentale chez les ruminants est constituée par l'ensemble des glandes salivaires. Le travail des glandes salivaires dépend bien entendu de la nature de l'alimentation : plus elle est sèche, ef plus le ruminant doit saliver. C'est ainsi que la quantité produite par un bovin par $24 \mathrm{~h}$ varie de 100 à 190 I (10 à $15 \mathrm{l} / \mathrm{kg}$ de matière sèche ingérée). La sécrétion est continue mais augmente fortement lors de la première prise alimentaire, et lors de chaque cycle de la rumination. La salive des ruminants a un pH franchement alcalin $(8$ à 8,5$)$, ce qui permet à l'animal de maintenir un équilibre acide-base convenable au niveau du rumen. $\mathrm{Ce} \mathrm{pH}$ basique est dû en grande partie au fait que la salive est riche en bicarbonate de sodium : le bovin secrète par jour de 1 à $1,5 \mathrm{~kg}$ de bicarbonate de sodium. On conçoit dès lors facilement le rôle de maintien du $\mathrm{pH}$ joué par la salive. On sait en effet, que chez les ruminants, grâce à une homéostasie précise, au niveau du rumen (anaérobiose, température constante de 30 à $40^{\circ} \mathrm{C}$, brassage périodique, teneur en eau comprise entre 75 et 85 p. 100), les micro-organismes peuvent se développer dans de très bonnes conditions. De plus, le transit est lent au niveau du rumen du fait de sa position en « cul-de-sac » sur le trajet des aliments. L'importance des micro-organismes a été précisée par Hungate (1942 et 1943) et a fait l'objet d'un article de synthèse intéressant en 1966 : cette micropopulation serait composée par $\mathrm{ml}$ de jus de rumen de bactéries $\left(10^{10}\right)$, de protozoaires ef de levures $\left(1^{6}\right)$. Selon les travaux récents de Bauchop (1979) des champignons inférieurs anaérobies (phycomycètes) participeraient activement à l'attaque des fibres végétales. Ces champignons possèdent une cellulase capable d'attaquer in vitro, des feuilles de papier filtre ou des fibres végétales. Leur efficacité au niveau du rumen serait d'autant plus grande que le régime est riche en fibres âgées et que le transit, par voie de conséquence est lent. Bauchop (1979) estime que le cycle complet des champignons est de $24 \mathrm{~h}$.

Le nombre el la nature de la micropopulation du rumen varient en fonction de la nature de l'alimentation, elle diminue en fonction du jeûne. Les micro-organismes 
dépendent donc complètement de l'apport alimentaire effectué par leur hôte. Mais à l'inverse, la micropopulation vit pour son propre compte. En définitive, le ruminant tire un « bénéfice » de cette symbiose car les micro-organismes sont seuls capables de digérer les aliments cellulosiques. De plus, ils réalisent des synthèses de vitamines et sont capables d'utiliser des formes d'azote non protéique (urée, ammoniaque) pour se multiplier. Le bilan sera positif pour le ruminant malgré l'existence d'actions spoliatrices de la part des micro-organismes, qui par leur métabolisme propre, libèrent dans le milieu de 1000 à 2000 I de gaz par jour, composés de $\mathrm{CO}_{2}, \mathrm{CH}_{4}, \mathrm{H}_{2}$, principalement, et de $\mathrm{NH}_{3}$ qui ne pourra pas toujours être utilisé en totalité par les micro-organismes et qui risquera donc d'intoxiquer le ruminant.

Envisageons quels sont les effets de la digestion microbienne sur les principaux constituants de la ration ingérés par les ruminants. Les sucres simples (fermentescibles) sont utilisés dans une proportion de 95 à 100 p. 100 par la micropopulation pour réaliser : 1) ses propres synthèses (donc multiplication de bactéries et de protozoaires qui représentent une source de matières protéiques de haute valeur); 2 ) produire et libérer dans le milieu des acides gras à courte chaîne dits acides gras volatils. Ces acides gras volatils ou AGV sont par ordre d'importance décroissante l'acide acétique, l'acide propionique ef l'acide butyrique, qui traverseront la paroi du rumen (Schambye, 1951) ef seront directement utilisés pour les besoins métaboliques de l'animal hôte. L'acide propionique pourra être converti en glucose, l'acide acétique participera à la synthèse des lipides du lait et l'acide butyrique accélèrera le catabolisme protéique et élèvera le taux sanguin des corps cétoniques.

Les micro-organismes sont également capables de produire ces AGV à partir de la cellulose. Cette digestion s'effectue grâce aux cellulases des micro-organismes. Dans ce cas, c'est l'acide acétique qui est le plus abondant, suivi des acides propionique et butyrique. Cetfe digestion de la cellulose est un phénomène extrêmement important et très intéressant puisque les ruminants arrivent à convertir en protéines des éléments végétaux inutilisables directement par l'homme.

Les protides de la ration sont également profondément remaniés par les microorganismes. Plus la protéine est soluble, et plus elle sera dégradée. Ceci peut être un sérieux handicap pour le ruminant. Le tannage des protéines alimentaires permet d'éviter leur digestion par les micro-organismes. Dans le cas d'une attaque microbienne, les protéines sont d'abord hydrolysées, il y a libération des acides aminés, qui sont ensuite désaminés avec production d'ammoniaque et de radicaux hydrocarbonés. Cet ammoniac servira à certaines bactéries ammoniophiles. De ce fait, à partir des protéines alimentaires, ou d'ammoniac, les bactéries font leurs propres synthèses, et en définitive, le ruminant ingère des protéines bactériennes. En résumé, ces synthèses bactériennes permettent au ruminant de convertir des protéines de valeur inégale en protéines de valeur biologique élevée et de profiter des vifamines synthétisées par les micro-organismes.

Les lipides sont également modifiés. Toutefois, pour une alimentation à base d'herbe, leur taux est peu élevé. Mais l'utilisation des lipides en alimentation peut s'avérer intéressante. D'après Bines (1976) l'augmentation du taux des lipides alimentaires chez le bovin permettrait un apport d'énergie efficace pour la production du lait et l'amélioration du taux butyreux, mais l'incorporation de grandes quantités de lipides 
dans la ration pose un certain nombre de problèmes. On sait que si le taux de lipides dépasse 8 p. 100, l'activité des micro-organismes du rumen se trouve considérablement perturbée. II fallait donc éviter que les micro-organismes n'attaquent les lipides. Wolter (1978) propose de disperser les lipides sur un support protéique et de tanner l'ensemble au formol. Ainsi, les lipides ne sont libérés que dans l'infestin du ruminant et les micro-organismes ne sont plus perturbés par un excès de lipides.

Les ruminants sont élevés en vue d'une production de viande, de lait ou de laine. Les rations préconisées en alimentation du bétail peuvent être déséquilibrées, ce qui produira parfois des troubles des métabolismes de la micropopulation, tels qu'acidose du rumen, alcalose du rumen, météorisations... (pour la pathogénie de ces maladies, on se reportera à l'article de Brugère-Picoux, Brugère et Le Bars, 1979).

\section{2. - Rôles du système nerveux central dans la régulation de la prise alimentaire.}

Les rôles du système nerveux central dans la régulation de la prise alimentaire sont extrêmement nombreux. Grâce à un ensemble très vaste de travaux, généralement élaborés à partir des monogastriques, et même de façon plus restrictive, chez le rat, on a réussi à proposer un schéma global du comportement alimentaire.

En définitive, il y a en présence, dans le comportement alimentaire, un aliment ef un animal (voir fig. 1) (Le Bars et Gallouin, 1972). L'aliment est examiné par l'animal

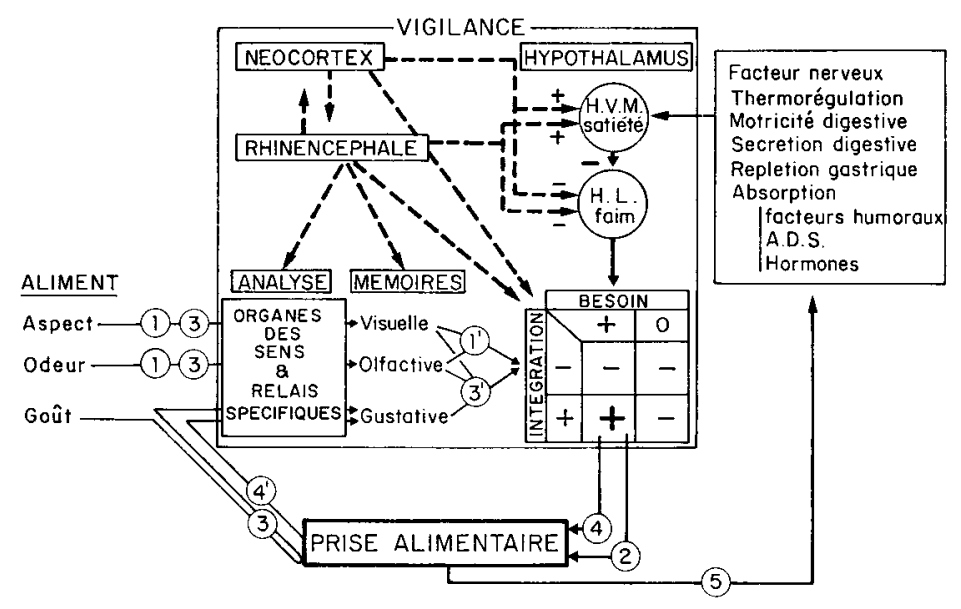

(1) Entrée des afférences visuelles et olfactives primitives. Après analyse elles sont intégrées ( $\left.1^{\prime}\right)$ par la mise en jeu des mémoires visuelles et olfactives, le rhinencéphale ef le néocortex. Si l'intégration de ces messages aboutit à la conclusion que l'aliment est comestible et si le besoin se fait sentir, une première prise de l'aliment s'effectue (2). Ce contact plus direct avec l'aliment (3) permet d'en connaître le goût ainsi que d'en confirmer l'aspect et l'odeur (3). L'intégration est effectuée maintenant avec 3 facteurs $\left(3^{\prime}\right)$. Si la comestibilité est confirmée le comportement alimentaire se poursuit $(4)\left(4^{\prime}\right)$. A ce moment la prise alimentaire peut intervenir par l'ensemble des réactions qu'elle provoque et modifie le niveau d'activité des noyaux ventro-médians hypothalamiques (5). Toute augmentation d'activité de ceux-ci inhibe le centre de la faim. Le besoin de manger est nul et le comportement alimentaire s'arrête.

à l'aide de deux systèmes sensoriels : la vision ef l'odorat. La vision lui permet de 
reconnaître cet aliment par l'analyse et l'intégration dans le système nerveux. L'odorat lui permet de comparer l'odeur qu'il reçoit au souvenir d'odeurs précédemment analysées et dont l'expérience alimentaire était favorable. L'intégration des messages visuel et olfactif indique à l'animal si l'aliment esi acceptable. C'est alors qu'intervient l'information centrale fournie par l'hypothalamus qui le renseigne sur l'amplitude de sa faim ou au contraire sur son rassasiement. Dans le cas de faim et après une première analyse, l'animal a un comportement moteur qui se traduit par l'ingestion d'une partie de l'aliment. A ce moment seulement, le goût de l'aliment est perçu et analysé de la même façon que les afférences olfactives ou visuelles. En cas d'acceptation en deuxième analyse, l'aliment est entièrement ingéré.

Le comportement alimentaire a ainsi commencé. Pour l'ensemble des animaux, l'aliment va donner secondairement le signal de l'arrêt du comportement ou rassasiement. Ce signal sera différent selon que l'on considère les animaux monogastriques ou les animaux ruminants. Chez les premiers, la prise de nourriture s'accompagne d'une multitude de phénomènes digestifs se traduisant par l'augmentation notable du taux de certains métabolites dans le sang. Par voie de conséquence, le système nerveux hypothalamique peut ainsi être renseigné sur les variations de la glycémie, du taux des acides gras, des acides aminés, etc...

Dans ces conditions, les noyaux ventromédians sont activés ef l'inhibition qu'ils exercent sur l'hypothalamus latéral ou centre de la faim augmente, c'est le phénomène de satiété.

Chez les ruminants il est évident que la satiété est déclenchée initialement beaucoup plus par le volume de la ration que par l'énergie qu'elle est susceptible d'apporter car la libération des nutriments dépend en grande partie de la micro-population du rumen qui ne présente une phase d'hyperactivité que vers la fin du repas. Chez ces animaux, la prise alimentaire est un phénomène de défense préventive et le véritable repas est en fait la rumination. Le phénomène de satiété initiale sera alors complété par un phénomène de rassasiement secondaire résultant d'une part, de la formation ef de l'absorption des acides gras à courte chaîne au niveau des réservoirs gastriques et de leur utilisation métabolique et, d'autre part, comme chez les monogastriques, de l'absorption des autres nutriments au niveau intestinal.

2.2.1. Rôles de l'hypothalamus. - En ce qui concerne l'existence des centres hypohalamiques et leur rôle physiologique dans la prise alimentaire, un «centre » situé dans la région médiane de l'hypothalamus peut être assimilé physiologiquement parlant à un centre de la satiété car sa destruction lève le frein qu'il exerçaif ef provoque l'hyperphagie. Une « aire » située dans l'hypothalamus latéral est identifiable à un centre de la faim. Cette conception est classique chez les monogastriques et établie à partir d'expériences réalisées chez le rat (Heterington et Ranson, 1939 ; 1942), chez la souris (Mayer et al., 1955), chez le singe et le chat (Anand, Dua et Shoenberg, 1956), chez le porc (Auffray 1969) et chez l'oie (Auffray et Blum, 1970). De plus, on admet généralement que le centre de la satiété (HVM) inhibe le centre de la faim (HL). Selon cette conception, c'est le phénomène de satiété qui serait essentiellement régulé Cette manière d'envisager le problème repose sans doute sur le fait qu'il y a beaucoup de preuves en faveur d'une régulation de la satiété par des facteurs métaboliques, alors qu'il est difficile de relier l'état de faim à une baisse d'un quelconque métabolite. 
II est également plus facile d'observer expérimentalement l'arrêt d'un repas que de déclencher une prise alimentaire.

Larsson (1954) a mis en évidence ces centres hypothalamiques chez la chèvre. II a montré qu'une stimulation électrique itérative des régions latérales de l'hypothalamus (aire périfornicale) permet la reprise du repas chez la chèvre rassasiée. Larsson observe que certains points stimulés déclenchent la rumination, ce sont les mêmes régions dont la stimulation entraîne l'hyperphagie (aire latérale).

Larsson a exploré d'autres régions et a montré que l'excitation du bulbe au niveau du noyau dorsal du vague pouvait produire l'hyperphagie.

A la même époque Dussardier et Albe-Fessard (1954) ont mis en évidence le centre vagal de la rumination ou plus exactement de l'activité réflexe des estomacs. Iggo (1955) a identifié grâce à des techniques électro-physiologiques des récepteurs gastriques capables d'informer ce centre. De plus, en 1956, il démontre que la section intercolliculaire (animal décérébré) ne supprime pas le réflexe de commande motrice par distension du réseau. Par conséquent, ces expériences démontrent que l'activité motrice (et la rumination) dépend d'un centre bulbaire, mais, Ruckebusch (1960 à 1963) précise qu'elle peut être modulée par l'hypothalamus. Wyrwicka et Dobrezcka (1960) produisent à l'inverse un arrêt de la consommation par stimulation des aires médianes (HVM) chez la chèvre conditionnée à la prise de nourriture. De plus, Ruckebusch (1963) a démontré chez le mouton qu'il était possible d'obtenir, selon la localisation des points de l'encéphale explorés, soit la prise alimentaire soit la rumination.

La prise de nourriture est obtenue pour une stimulation itérative de la région comprise entre le troisième ventricule et le fornix, et ceci malgré « un état d'inconfort assez accusé de l'animal ». La même stimulation quand le mouton est préalablement gavé déclenche une incitation à la prise de nourriture mais elle n'est pas suivie d'effet. Cette expérience nous semble particulièrement intéressante, elle tend à prouver en effet que les facteurs d'encombrement de la ration « domineraient » les autres processus alimentaires. Ruckebusch, dans ce même travail démontre qu'il est possible d'obtenir la rumination par stimulation d'autres points situés dans les régions plus profondes et plus postérieures. Le comportement ainsi obtenu est très semblable à ce que l'on observe spontanément.

En 1968, avec Laplace, Ruckebusch étudia de façon très complète les effets à long terme des excitants corticaux, des antidépresseurs non IMAO ou IMAO ${ }^{(1)}$ et des principaux vomitifs sur le niveau d'ingestion, le temps de prise de nourriture, le temps de rumination, le nombre de cycles méryciques et l'état de vigilance du mouton adulte. D'un point de vue qualitatif, ces auteurs ont montré que l'injection de mescaline, apomorphine, morphine, amphétamine provoque un syndrome général d'excitation avec comportement oral stéréotypé. Ce comportement ne doit pas être confondu avec la prise de nourriture car il n'y a pas en effet d'ingestion alimentaire. La mescaline, à la dose de $2 \mathrm{mg} / \mathrm{kg} \mathrm{IM}$ provoque des mâchonnements et des mastications à vide (comportement oral) durant près de $6 \mathrm{~h}$. L'apomorphine, chez le mouton, par voie intraveineuse ou intramusculaire $(0,1 \mathrm{mg} / \mathrm{kg})$ n'est suivie que d'excitation avec comporte-

(1) IMAO : inhibiteur de la monoamineoxidase, enzyme qui, au niveau de l'élément pré-synaptique, régule le stockage et la disparition des neuro-transmetteurs comme l'adrénaline. 
ment oral alors que chez les carnivores elle déclenche le vomissement. La morphine, par voie intracérébrale, déclenche un comportement oral ressemblant à la prise de nourrifure, mais sans augmentation des quantités ingérées. L'amphétamine (bétaisopropylamine), à la dose d'1 $\mathrm{mg} / \mathrm{kg}$, réduit la quantité d'aliments ingérés. Ces auteurs, ont de plus montré qu'il était possible de dissocier la prise alimentaire de la rumination. C'est ainsi qu'il est possible de diminuer seulement le temps de rumination par trois groupes de substances : groupe des antidépresseurs IMAO, groupe des cardiotoniques digitaliques et groupe des cyto-statiques.

A l'inverse, il est possible d'augmenter le seul temps de rumination avec l'ouabaine et la théophylline, mais cet effet ne semble pas constant. Des substances s'avèrent très efficaces pour réduire ou augmenter la prise de nourrifure et le temps de rumination. La réduction de la prise de nourriture et du temps de rumination s'observe à la suite d'administration d'imipramine (tofranil), d'amphétamine, d'éphédrine, de caféine, de méthylphénidate (ritaline), de mescaline et d'atropine. L'augmentation de la prise de nourriture et de la rumination est observable, à long terme, après injection IM de chlorpromazine (largactil) et, à court terme, après injection dans le liquide céphalo-rachidien de pentobarbital (nembutal). Ces essais démontrent donc, chez les ruminants, trois faits nouveaux : 1) il est possible de provoquer un comportement oral stéréotypé identique à celui rencontré chez les rongeurs ; 2) les réponses observées sont très nettes en ce qui concerne l'arrêt de la prise alimentaire (satiété à court terme); 3 ) il est possible de dissocier totalement l'ingestion de la rumination alors que ces deux phénomènes sont en relation étroite par l'intermédiaire de la quantité ef de la qualité d'aliments ingérés.

A la même époque, Bost et al. (1967) ont montré chez le mouton que l'injection intraveineuse lente de deslanoside abolit toute rumination pendant 10 à $15 \mathrm{~h}$ et que l'ingestion alimentaire n'est pratiquement pas perturbée. A l'inverse, l'injection cérébro-ventriculaire (exclusivement) de morphine déclenche de la boulimie avec mastication ininterrompue mais, supprime toute rumination pendant 10 à $15 \mathrm{~h}$. Ces mêmes auteurs ont de plus démontré que l'ablation chirurgicale de l'area postrema ne modifie pas la réponse à la morphine mais abolit l'inhibition de la rumination à la suite de l'administration de deslanoside. L'area postrema est connue chez les monogastriques comme étant une région de la medulla oblongata chémosensible capable d'induire le vomissement à la suite de l'injection sous-cutanée d'apomorphine. Les résultats de cette expérience démontrent que bien qu'il existe des ressemblances entre le vomissement ef la rumination, ces deux phénomènes ne sont pas comparables ef sont commandés par des structures différentes. On savait depuis les travaux de Guinard (1898), cité par Bost (1958), que l'apomorphine n'était pas émétique chez les ruminants adultes. Bost, Boivin et Ribot (1969) démontrent que chez le jeune agneau âgé de 3 à 31 jours, l'injection IV d'apomorphine fait apparaître après quelques minutes de latence, un « syndrome boulimique » spectaculaire (comportement oral), mais sans augmentation du niveau d'ingestion alimentaire. "Tout se passe comme si l'apomorphine stimulait puissamment les phases initiales d'un comportement alimentaire de type adulte (et celles-ci seulement) : exploration et recherche de la nourriture, préhension ef mastication. De plus, ce comportement s'exerce sans discrimination vis-à-vis des substances solides alibiles ou non. »Cette expérience permet de supposer que le ruminant adulte 
n'est autre chose qu'un monogastrique qui a évolué et non un animal différent. On peut penser que la régulation de la prise alimentaire chez le ruminant adulte n'est pas fondamentalement différente de celle des monogastriques : toutes les expériences qui ont été réalisées jusqu'à ce jour démontrent les similitudes existant entre ces divers groupes d'animaux. Il n'en demeure pas moins vrai qu'il existe quelques différences que nous essayons d'analyser dans cet exposé.

Quelle est la signification physiologique de la rumination ? Les expériences de Bost et al. (1967) entreprises sur le mouton ont permis d'inhiber la rumination pendant une période de $15 \mathrm{~h}$. Quelles en étaient les conséquences sur la digestibilité de la ration? Jean-Blain, Boivin et Bost (1971) entreprirent de bloquer la rumination et d'éłudier la digestibilité de régime varié (foin long, foin long et concentrés, luzerne déshydratée en pellets, luzerne en bouchons à longs brins, maïs déshydraté en pellets). Ces auteurs concluent : « ... l'étude parallèle des coefficients d'utilisation digestive avec des régimes variés montre que cette réduction du temps de rumination s'accompagne d'une augmentation de la digestibilité de la cellulose, de la matière sèche et à un moindre degré de l'azote. Ces résultats apparemment paradoxaux confirment cependant les travaux antérieurs et apportent des arguments en faveur d'une conception restrictive du rôle physiologique de la rumination. Loin de favoriser la digestion bactérienne, elle déprime au contraire, l'utilisation digestive des aliments. Par contre, elle aurait pour effet d'accélérer le transit digestif et d'augmenter en fin de compte l'ingestion alimentaire ».

Baile, Mahoney et Mayer (1967a) démontrent qu'il est possible d'obtenir une hyperphagie durable chez la chèvre à la suite de l'électrocoagulation de l'aire ventromédiane de I'hypothalamus. Holmes et Frazer (1965) n'avaient pas pu la produire par des techniques équivalentes appliquées à la brebis. Baile et Mayer (1966) avaient observé l'apparition d'hyperphagies fugaces à la suite de l'injection au voisinage des noyaux ventro-médians, de petites quantités de pentobarbital. Pour ces auteurs, il devenait évident que l'anesthésie des structures médianes était l'équivalent d'un bloquage temporaire du centre de la satiété. Leurs premières expériences ont été réalisées sur des chèvres adultes alimentées à l'aide d'une ration concentrée contenant 9 p. 100 de fibres distribuée ad libitum et de $200 \mathrm{~g}$ de foin d'herbe. Un animal a particulièrement bien réagi puisque son poids a augmenté de 150 p. 100 en 3 mois. Pour Baile et Mayer (1966), l'insuccès de Holmes et Frazer tient au fait que les brebis de ces derniers sont alimentées exclusivement à base de foin et par conséquent par un régime à énergie faible par rapport à l'encombrement qui limite, dans ce cas, l'ingestion. Cette remarque précise encore le rôle essentiel de l'encombrement de la ration au niveau de la régulation de l'ingestion des ruminants.

L'ensemble de ces expériences démontre que l'hypothalamus des ruminants n'est pas fondamentalement différent dans son organisation et dans son fonctionnement de celui des rongeurs, des porcins ou même des oiseaux (poulets, oies) puisque les mêmes lésions produisent les mêmes effets chez toutes ces espèces.

Peterson, Baile et Baumgardt (1972) ont vérifié chez le mouton et chez le veau que l'hyperphagie pouvait être également induite à la suite d'injection de pentobarbital dans le liquide céphalo-rachidien. Des travaux postérieurs sur le mouton (Seoane, Baile et Webb, 1973) ont de plus montré que les barbituriques à action de longue durée 
étaient plus efficaces pour produire l'hyperphagie que des médicaments à action brève.

A la suite des travaux cités ci-dessus de Ruckebusch et al., de Bost et al., de Baile ef al., de nombreuses recherches ont été entreprises de façon à essayer de connaître le mode de fonctionnement des centres hypothalamiques. Un ensemble de travaux a été réalisé pour connaître le rôle des cations au niveau des neurones centraux impliqués dans la prise alimentaire. L'excitabilité neuromusculaire peut être modifiée selon Loeb par deux groupes de cations. Certains se comportent comme des calmants ( $\mathrm{Ca}^{++}$, $\left.\mathrm{Mg}^{++}\right)$tandis que d'autres sont comparables à des excitants $\left(\mathrm{Na}^{+}, \mathrm{K}^{+}\right)$. Qu'en est-il au niveau du système nerveux central ? Si le noyau ventromédian est bien assimilable à un centre de la satiété, à chaque fois qu'il est excité (par des facteurs nerveux ou métaboliques) il doit induire une baisse de la prise alimentaire, et, réciproquement, s'il est déprimé, son action inhibitrice sur l'aire latérale ne se fait plus sentir et la prise alimentaire doit avoir lieu. C'est ainsi que $\mathrm{Ca}^{++}$ou $\mathrm{Mg}^{++}$injectés dans le liquide céphalorachidien du mouton déclenchent la prise alimentaire, alors que $\mathrm{Na}^{+}$et $\mathrm{K}+$ l'inhibent (Seoane et Baile, 1973). Ca $\mathrm{a}^{++}$et $\mathrm{Mg}^{++}$, cations calmants, ont donc la même action que les barbituriques (qui sont eux-mêmes des dépresseurs). Par quels mécanismes ces cations agissent-ils sur la prise alimentaire? Aucune expérience, à notre connaissance, n'est venue apporter jusqu'à présent, une quelconque lumière sur ce problème.

Depuis les travaux de Soulairac (1958 et 1962) on supposait que les phénomènes de satiété étaient commandés par l'adrénaline ou la noradrénaline, tandis que les manifestations de la faim obéissaient à l'acétylcholine. Le développement relativement récent des techniques histochimiques utilisant la fluorescence des catécholamines, a permis de les identifier et de les localiser dans les différentes structures cérébrales. On a pu établir une véritable carte de neurones utilisant comme neurotransmetteurs la noradrénaline, la dopamine ou la sérotonine (Ungerstedt, 1971a). Mais avant ces preuves décisives, un ensemble de travaux avait déjà permis de cerner assez bien le problème. Ainsi Grossman (1962) a trouvé que l'adrénaline déposée sous forme cristallisée dans l'hypothalamus augmente l'ingestion alimentaire chez le rat. Leibowitz (1970a ef $b$, 1971) a démontré chez le rat, l'existence de récepteurs adrénergiques de type $\alpha$ et $\beta$ pouvant réguler la soif et la faim. Rappelons que l'adrénaline agit à la fois sur les 2 types de récepteurs, tandis que la noradrénaline n'agit que sur les récepteurs $\alpha$ ef l'isoprotérénol sur les récepteurs $\beta$. Les récepteurs adrénergiques $\alpha$ ef $\beta$ peuvent être spécifiquement bloqués par, respectivement, la phentolamine ( $\alpha$ antagoniste) ef le propranolol ( $\beta$ antagoniste). Un agent $\alpha$ injecté dans l'hypothalamus médiolatéral (aire périfornicale) déclenche la prise alimentaire sur un animal apparemment rassasié, fandis qu'un agent $\beta$ produit l'effet inverse. La phentolamine bloque l'effet du produit agissant sur les récepteurs $\beta$ (prise alimentaire) tandis que le propranolol inhibe la satiété.

Si l'on combine l'action d'un agent $\beta$ (provoquant la satiété) et celle d'un $\alpha$ antagoniste, l'effet rassasiant de l'agent $\beta$ se trouve augmenté. Les injections faites par Leibowitz (1970 $a$ et $b, 1971)$ étaient pratiquées dans la région périfornicale, c'est-à-dire sensiblement entre le noyau ventromédian hypothalamique et l'aire latérale. Cet auteur a précisé par la suite que les récepteurs $\alpha$ étaient préférenłiellement situés dans l'hypothalamus médian et que les récepteurs $\beta$ se trouvaient dans l'aire hypothalamique latérale. On peut donc imaginer l'existence de deux systèmes complémentaires, deux 
centres à récepteurs de type $\alpha$ et $\beta$, autrement dit, un centre de la faim et un centre de la satiété. Notons que les effets $\alpha$ et $\beta$ ne sont pas toujours très purs, on a même pu diviser les récepteurs $\beta$ en $\beta 1$ ef $\beta 2$. Baile et al. (1974a) ont vérifié en partie chez le mouton, les expériences déjà réalisées chez le rat par Leibowitz (1970a, b, 1971). La prise alimentaire a pu être augmentée avec une injection intracérébrale (in situ) de noradrénaline (substance agissant sur les récepteurs $\alpha$ ou $\alpha$ agoniste). L'isoprotérénol (agent $\beta$ agoniste) induit aussi la prise alimentaire. Bien que les noyaux hypothalamiques qui donnent le maximum de prise alimentaire après action des agents $\beta$ ou $\alpha$ soient différents, il n'a pas été mis en évidence, chez le mouton, de noyaux qui possèdent les effets $\alpha$ ou $\beta$ exclusivement. Toutefois, les substances antagonistes des effets $\alpha$ et $\beta$ bloquent de façon spécifique les agonistes $\alpha$ et $\beta$ correspondants. Ces auteurs en concluent que les récepteurs $\alpha$ et $\beta$ sont capables de transmettre de la même façon, les signaux qui commandent la prise alimentaire chez le mouton. Il n'a pas été possible de préciser le rôle des $\beta 1$ et des $\beta 2$ récepteurs. Les injections dans l'hypothalamus latéral, de substances à effet $\alpha$ ou $\beta$ à quelque dose que ce soit, n'ont pas d'action sur la prise alimentaire. On ne retrouve donc pas, semble-t-il, chez le ruminant, d'opposition aussi nette entre effets $\beta$ ef $\alpha$. Des expériences antérieures de Baile, Martin, Simpson (1972a) et Baile ef Martin (1972b) réalisées chez le mouton et les bovins avaient permis d'obtenir des effets plus proches de ceux trouvés chez les rongeurs. Il est vrai que les premières expériences étaient effectuées par des injections des agents $\alpha$ et $\beta$ dans le liquide céphalorachidien, et de ce fait, les substances diffusant plus, touchent de nombreuses structures pouvant avoir des effets opposés. En l'état actuel de nos connaissances, il n'est donc pas possible de préciser quels sont les effets exacts des agents $\alpha$ et $\beta$ sur la prise alimentaire ef la satiété chez les ruminants.

Des expériences complémentaires ont été réalisées chez le rat par Van der Gugten et Slangen (1977) : elles ont consisté en la mesure des catécholamines spontanément libérées in situ au cours de la prise alimentaire et de boisson. Pendant la prise alimentaire, la noradrénaline est libérée massivement à partir des aires sub- et périfornicales. Les quantités de noradrénaline mesurées pendant l'ingestion sont de 40 à 50 p. 100 plus élevées que pendant les périodes pré ou postprandiales. Il n'y a pas d'augmentation du taux de dopamine pendant la même période, ni d'élévation du taux d'adrénaline durant la prise de boisson. Ces expériences sont en accord avec celles de Leibowitz (1971) chez le rat et, bien qu'elles n'aient pas été réalisées chez les ruminants, on peut penser qu'elles permettraient d'aboutir aux mêmes conclusions.

Croze et Bost (1974) ont abordé le problème de l'intervention des catécholamines dans la prise alimentaire des ruminants, de manière sensiblement différente. Ils étudièrent l'effet d'un IMAO : la nialamide, en s'opposant à l'action de la monoamine oxydase, aboutit à l'accumulation, par diminution du catabolisme, des amines cérébrales. Pour ces auteurs, l'utilisation de la nialamide revient donc à étudier l'effet d'une augmentation des catécholamines. Chez le mouton, l'injection intracérébrale de nialamide provoque une élévation très nette de la prise alimentaire (qui double) et de la rumination. A l'inverse, une injection cérébro-ventriculaire de 6-hydroxy-dopamine, connue depuis les travaux de Clarke, Smookler et Hadinata (1972) comme étant capable de provoquer une déplétion durable des catécholamines, se traduit par une baisse de la prise alimentaire $(50$ p. 100$)$ ef du temps total de rumination. Ces deux expériences 
confirment donc de façon certaine que les catécholamines exogènes ou endogènes interviennent dans la prise alimentaire des ruminants. Toutefois, la deuxième expérience de Croze et Bost laisse planer deux incertitudes car la 6-hydroxy-dopamine a plusieurs effets : elle détruit sélectivement les terminaisons nerveuses noradrénergiques et dopaminergiques, sans toucher les terminaisons sérotoninergiques (Ungerstedt, 1971). Les auteurs pensent que certains effets observés précocement (accélération du rythme de contraction du réseau) après l'injection de 6-hydroxydopamine pourraient être dus à la déplétion en dopamine.

Dans certaines espèces comme l'oie (Auffray et Gallouin, 1971) l'injection dans le troisième ventricule d'une dose unique de 250 à $500 \mu \mathrm{g}$ de 6-hydroxydopamine provoque une hyperphagie phénoménale. L'oie ingère de 2 à 3 fois plus de matière sèche par jour, l'hyperphagie dure au moins un mois, ce qui aboutit à un état d'obésité et même, en général, à la formation d'un foie gras. L'effet est donc absolument opposé à celui trouvé chez le mouton. Dans les expériences de Croze et Bost, les injections sont réalisées dans les ventricules latéraux, tandis que les injections chez l'oie avaient lieu très lentement dans le troisième ventricule et au voisinage immédiat du noyau ventromédian : les divergences dans les résultats tiennent sans doute aux différences de technique de perfusion. Cela n'est pas improbable quand on connaît l'extrême labilité de la molécule de 6-hydroxydopamine, même si elle est protégée de l'oxydation grâce à la vitamine $C$. Elle doit être, en outre, littéralement pompée par les récepteurs situés au voisinage du point d'injection, ce qui peut expliquer encore les différences d'action constatées. On peut aussi simplement dire que les ruminants sont difficilement comparables aux oiseaux.

Barreft (1978), dans une revue consacrée à l'étude de la neuropharmacologie, conclut qu'il est difficile de proposer une théorie cohérente de la régulation de la faim à l'aide des expériences de neuropharmacologie. Il insiste aussi sur le fait que beaucoup d'expériences réalisées sur l'animal sont difficilement extrapolables à l'homme.

Vers les années 1970, la biochimie des prostaglandines s'étant développée, un ensemble de travaux a laissé penser qu'elles pouvaient jouer un rôle dans la transmission nerveuse et notamment agir comme facteur de contrôle des réserves de lipides de l'organisme. Dans cet esprit, Baile ef al. (1974b) étudièrent l'effet d'injections directes dans l'hypothalamus de certaines prostaglandines et de leurs antagonistes. Les injections furent réalisées aux endroits précis de l'hypothalamus médian et antérieur dont

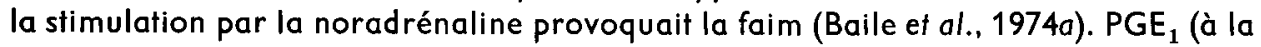
dose de 14 et 28 nanomoles) réduit la prise alimentaire spontanée pendant une heure maximum. $P G E_{2}$ esł sans effet. $P G E_{1}$ injecté dans l'hypothalamus antérieur et latéral (région qui ne réagissait pas à la noradrénaline) produit, à l'inverse, une augmentation de la prise alimentaire qui dure plus d'une heure. Les antagonistes des prostaglandines (phosphate de polyphlorétine, acide oxaprostinoïque...) ne sont pas tous actifs sur la prise alimentaire. Une injection de 6 nmoles de phosphate de polyphlorétine produit les effets inverses de la prostaglandine. Dans ce très important travail, Baile et al. (1974b) établissent les relations qui lient les agents testés comme actifs au niveau de l'hypothalamus antérieur. C'est ainsi que la noradrénaline, agent $\alpha-$ agoniste, déclenche la faim, alors que dans le même site, $\mathrm{PGE}_{1}$ l'inhibe. Dans ce cas, on peut donc considérer $\mathrm{PGE}_{1}$ comme un antagoniste de la noradrénaline. Le phos- 
phate de polyphlorétine. inhibiteur de $\mathrm{PGE}_{1}$ a un effet comparable à la noradrénaline ; son action se manifeste peut-être par l'intermédiaire de la libération de la noradrénaline. En bloquant $\mathrm{PGE}_{1}$ le phosphate de polyphlorétine permet peut-être une plus grande libération de noradrénaline. Il est également possible que l'effet du phosphate de polyphlorétine soit indépendant de $\mathrm{PGE}_{1}$ car il a été montré (Diezfalusy et al., 1953, cité par Baile, 1974b) qu'il a des propriétés inhibitrices sur les enzymes en culture de tissus.

Nous avons vu précédemment (Seoane et Baile, 1973) que le calcium injecté dans l'hypothalamus ou le liquide céphalo-rachidien produisait la prise alimentaire. Cet effet peut s'expliquer par une inhibition de $\mathrm{PGE}_{1}$ par le calcium. Le calcium inhibant un inhibiteur facilite par conséquent un processus : l'induction de la prise alimentaire, grâce à un accroissement de la libération de la noradrénaline.

Pour Baile ef al., il est possible que la noradrénaline, les prostaglandines ef le calcium agissent sur un même récepteur impliquant également l'action de l'adénylcyclase. Des arguments apportés par Robinson, Butcher et Sutherland (1970) sont avancés par Baile et al. comme explication de ces interrelations : " dans ce système (hypothalamus), et à un degré moindre dans d'autres tissus, les agents $\alpha$ agonistes suppriment apparemment l'adénylcyclase, tandis que les agents $\beta$ agonistes augmentent l'activité de l'adénylcyclase... ». Ceci n'est qu'une hypothèse, car des drogues comme l'isoprotérénol (agent $\beta$ agoniste) produisent également la faim quand on l'injecte dans les mêmes régions.

Baile ef al. (1974b) dans leur revue, concluent qu'il est très difficile d'attribuer à $\mathrm{PGE}_{1}$ un rôle dans le contrôle des réserves de lipides de l'organisme (car PGE $\mathrm{F}_{1}$ a beaucoup d'effets différents), mais qu'elle pourrait avoir un rôle important dans la modulation de la neurotransmission.

Voici donc quels sont les facteurs intrinsèques intervenant dans le fonctionnement des centres de la faim et de la satiété. L'existence d'un centre de la faim et d'un centre de satiété a été prouvée par des expériences de stimulation et de destruction. Les synapses des neurones formant ces centres admettent vraisemblablement comme neurotransmetteur la noradrénaline (ou/et peut-être la dopamine) : cette conception a pu être établie à la suite de l'utilisation de substances comme les $\alpha$ et $\beta$ bloquants, les IMAO, la 6-hydroxy-dopamine. Le $\mathrm{Ca}^{++}$ef le $\mathrm{Mg}^{++}$dépriment ces neurones et produisent la prise alimentaire au même titre que les barbituriques. La prostaglandine $\mathrm{PGE}_{1}$ se comporte comme un agent antagoniste de la noradrénaline et intervient peut-être dans la régulation de sa libération. Il est certain que d'autres facteurs physiologiques peuvent intervenir au niveau hypothalamique pour moduler la faim ou la satiété : en particulier l'hormone de la satiété, ou satiétine, qui semble être isolée aujourd'hui par Knoll (1979) à partir du sérum humain, et qui aurait une faible spécificité zoologique, puisqu'elle produirait une hyperphagie très accusée et durable chez le rat. Cette question sera développée au chapitre 3.

Facteurs humoraux extrinsèques pouvant modifier le fonctionnement hypothalamique.

La simple observation du monde animal actuel nous invite à croire que si les espèces ont pu évoluer et subsister, c'est qu'elles avaient la possibilité de régler la qualité et la quantité de leurs ingesta en fonction de leurs besoins. L'animal en liberté doił 
pouvoir faire un choix alimentaire en fonction de ses besoins et il peut discerner les aliments indispensables de ceux qui ne le sont pas. Sur le plan quantitatif, ef malgré une grande variation des dépenses quotidiennes, l'animal, de même que l'homme, est capable d'ajuster sa prise alimentaire à ses besoins. La précision de l'ajustement calorique à long terme chez l'homme est remarquable : le poids de la prise alimentaire ne varie pas de plus de 1 p. 100 durant 40 à 50 ans.

A court terme, chez un animal adulte en situation de dépense énergétique moyenne et stable, la consommation quotidienne est constante à 10 p. 100 près, ce qui a une incidence pondérale de 1 p. 100 environ (Le Magnen, 1976). Dans le cas où l'homme est mis en présence d'une alimentation à densité calorique différente, l'ajustement s'effectue après quelques jours. C'est, d'après Le Magnen (1976), par le jeu du conditionnement de la palatabilité que se réalise l'ajustement de la consommation aux différentes valeurs caloriques des aliments. Ceci suppose donc que le cerveau soit renseigné sur le manque ou l'excès en tel ou tel élément, bien que l'homme ou l'animal n'en ait pas conscience. Cette notion met l'accent sur un déterminisme essentiellement chimique de l'ingestion : le comportement alimentaire apparaît comme un chimiotropisme. Il y aurait ainsi des faims spécifiques pour les diverses catégories d'aliments, conditionnées par le taux des nutriments dans le sang (Le Bars et Gallouin, 1972).

De nombreux travaux démontrent que l'ingestion alimentaire est liée à la dépense énergétique : les mécanismes réglant la consommation énergétique doivent avoir une partie commune avec ceux intervenant dans le contrôle des échanges énergétiques, la dépense d'énergie se traduit toujours par une élévation thermique : s'il est sensible à la dépense énergétique, l'hypothalamus doit pouvoir mesurer la variation de température et ajuster les entrées en conséquence. La dépense peut s'effectuer sous forme de glucides, lipides, acides gras, protides. On doit donc admettre au niveau hypothalamique, l'existence de structures sensibles aux glucides, aux lipides, aux acides gras volatils, aux protides... Différents auteurs, en fonction des nutriments utilisés par l'animal, ont émis des hypothèses pour expliquer l'importance de ces nutriments en tant que régulateurs métaboliques de la consommation alimentaire. Or, nous verrons qu'aucune «constante biologique » simple ne semble directement responsable de la mise en jeu des centres nerveux de la faim ou de la satiété. Le fait qu'aucune de ces hypothèses prise isolément ne donne entière satisfaction n'est pas surprenant car, d'une part, l'état de besoin de l'organisme est complexe et ne dépend pas d'un seul facteur métabolique ef, d'autre part, il existe des interrelations entre les métabolismes des substances organiques. Cependant, la discussion de ces hypothèses est utile car, c'est seulement en connaissant le rôle des divers métabolites en tant qu'agents d'information du système nerveux central qu'on peut se rendre compte du mécanisme général du contrôle de l'apport des nutriments.

2.2.2. Rôles de la formation réticulaire. - Le fonctionnement des centres nerveux est restructuré, remanié pendant les phases de sommeil, que ce soit le sommeil à ondes lentes (SWS) ou à ondes rapides (sommeil paradoxal) on démontre que le cerveau consomme la même énergie. Le sommeil n'est pas une mise au repos du cerveau. Cette modification du fonctionnement des centres nerveux est suivie de l'abolition du comportement alimentaire.

La formation réticulée est caractérisée du point de vue architectonique par des 
associations extrêmement étroites entre les cellules qui la constituent (on a pu calculer que chaque neurone réticulaire est relié par des extrémités axoniques à 26000 autres neurones). Ces neurones sont situés dans le mésencéphale, le pont de Varole et le bulbe, et remplissent les espaces entre les noyaux spécifiques et les faisceaux de fibres nerveuses. Un point très important doit être signalé ici : la formation réticulée, de par son architectonie, a la propriété de réagir dans son ensemble en déterminant une réaction d'éveil de l'animal quel que soit l'endroit de cette structure atteint par la stimulation électrique. La formation réticulée reçoit des afférences de la moelle, du cervelet, du cortex cérébral et de tous les systèmes sensoriels. Elle envoie des efférences descendantes médullaires et des efférences ascendantes à la totalité des structures cérébelleuses et cérébrales. On peut, grâce à des enregistrements réalisés à travers le scalp, ou à l'aide d'électrodes implantées de façon chronique sur la dure mère, enregistrer l'activité des neurones du cerveau. Durant les phases d'éveil comportemental, les tracés électriques sont caractérisés par des ondes de petite amplitude et de fréquence élevée. Pendant l'assoupissement comportemental, facile à faire disparaître grâce à une stimulation légère de l'animal, l'amplitude des ondes du tracé EEG augmente mais la fréquence diminue : on dit qu'il y a « une synchronisation » des activités corticales. Pendant le sommeil comportemental, il apparaît régulièrement des épisodes «paradoxaux ». Le paradoxe naît de l'aspect insolite du tracé EEG qui ressemble à celui d'un animal éveillé, contrastant cependant avec un relâchement total des muscles squelettiques. Toutefois, les muscles des yeux peuvent être l'objet de contractions rapides faisant tourner les globes oculaires rapidement (sommeil REMS, rapid eyes movements sleep).

Des éfudes éthologiques démontrent que les ruminants dorment peu de temps à chaque fois et que le plus souvent le sommeil est léger. De plus, dans la nature, ils vivent en général en troupeaux ef certains animaux veillent tandis que d'autres dorment. Il est en effet nécessaire de surveiller l'approche des prédateurs. Le sommeil léger apparaît quand l'animal est sevré. En effet, le veau, ou l'agneau à la mamelle, a un comportement de sommeil identique à celui des autres monogastriques.

Balch (1955) a étudié le sommeil chez la vache et a constaté que les périodes de rumination alternent avec le sommeil et la prise alimentaire.

Munro (1957), chez la brebis, en suivant l'évolution du sommeil en fonction de l'âge, précise que le sommeil profond disparaît au moment du sevrage.

Bell (1958) grâce à l'électroencéphalographie (EEG), met en évidence que les périodes de rumination s'observent alors que le tracé EEG correspond à un état de somnolence.

Ruckebusch (1960) a étudié les relations entre sommeil paradoxal, sommeil lent, rumination et prise alimentaire. II a tout d'abord démontré chez la chèvre adulte (1963) que l'endormissement et le sommeil à ondes lentes apparaissaient encore au cours de la rumination (60 p. 100 de la rumination se produit pendant cette phase de sommeil), et que le sommeil à ondes rapides (sommeil paradoxal) durait seulement 5 à 10 min.

L'activité corticale est très proche chez le nouveau-né de celle de l'adulte ; dès la naissance, les alternances veille-sommeil sont très nettement caractérisées chez l'agneau. Le nombre de tétées est de $40 / 24$ h à 2 jours, 26/24 h à 8 jours et 14/24 h à 1 mois (Ruckebusch, 1963) et ce qui est remarquable, 3 tétées seulement durant la nuit. 
A partir d'un mois, l'ébauche d'un cycle veille-sommeil est amorcée. Selon Ruckebusch (1963) l'unique prise alimentaire du matin (condition expérimentale) esł suivie de 12 périodes de rumination durant lesquelles surviennent quelques phases de sommeil lent. A l'âge de 6 mois, les phases de sommeil paradoxal ne représentent que 3 à 4 p. 100 du sommeil comportemental et elles ne surviennent que la nuit. Selon cet auteur, il est possible de provoquer la synchronisation corticale (d'obtenir un tracé EEG à ondes lentes) par stimulation de la corne d'Amon mais à condition que l'animal soit déjà au repos. Si l'animal mange, il n'y a pas synchronisation.

Ruckebusch a pu obtenir la synchronisation de l'EEG par stimulation du thalamus médian quel que soit le degré de vigilance et après stimulation de l'aire préoptique. « II est remarquable de constater qu'aucune des zones stimulées n'induit un comportement mérycique et ce, malgré l'apparition d'une synchronisation corticale. Ce dernier point nous fait penser que si le déclenchement de la rumination est facilité par un repos sensoriel, il n'a rien à voir avec le cycle veille-sommeil. L'apparition d'ondes lentes sur le plan EEG au cours de la rumination s'expliquerait par le fait que l'animal peut s'endormir en ruminant. » Ce travail de thèse a été poursuivi par Ruckebusch ef son équipe. Citons le travail de Ruckebusch et Bell (1970 et 1972) chez la vache, Ruckebusch ef Bueno (1972) sur l'analyse des relations vigilance ef activité alimentaire chez les bovins en stabulation. Puis, en 1974 avec Dougherty et Cook, il établit la relation entre le mouvement des mâchoires, la motricité du rumen et l'état de sommeil.

Bell et ltabisashi (1973) arrivent sensiblement aux mêmes conclusions. Grâce à des analyses séquentielles de l'EEG au cours du nycthémère, ils remarquent que les moutons ou les chèvres, pendant le sommeil, peuvent avoir des habitus très différents (debout, couché ou en rumination). La rumination, généralement, est suivie de sommeil paradoxal, ce qui suggère qu'elle se produit souvent quand le ruminant sommeille. Le sommeil paradoxal survient toujours après le sommeil lent. Le jeûne réduit le temps de rumination mais ne change pas l'apparition ef la durée des phases du sommeil.

Dallaire, Toutain et Ruckebusch (1974) en comparant la durée du cycle du sommeil chez le poney, la chèvre et la vache à celle d'autres espèces établissent que la durée du sommeil n'est pas en relation directe avec le poids métabolisable de l'espèce considérée mais qu'il existe une relation entre le coefficient d'encéphalisation (rapport du poids du cortex cérébral au poids du tronc cérébral) et le sommeil. Plus un animal est « corticalisé », et plus il dort. Le sommeil dépend également de «l'état métabolique du sujet »s.

Ruckebusch et Gaujoux (1976) constatent chez le mouton qu'un régime à teneur élevé en azote (l'augmentation d'azote se fait sous forme d'urée) a un effet hypnogène. Cette expérience établit les relations entre des facteurs humoraux et le sommeil. A l'inverse, on peut penser que le manque d'un nutriment précis provoque l'éveil et la recherche de la nourriture pour trouver l'élément manquant.

Récemment, Tindal et al. (1978) ont établi les corrélations entre la libération de l'hormone de croissance chez la chèvre en lactation ou tarie avec le comportement alimentaire, les états de sommeil, l'EEG, le niveau de prolactine, d'insuline, la glycémie et le taux des acides gras libres circulants. Cette étude très complète n'a pas permis d'établir de relation entre la libération de l'hormone de croissance et les états de sommeil. Il convient de souligner que l'hormone de croissance chez les ruminants est plus 
importante que la prolactine dans le maintien de la lactation. Par contre, les auteurs précisent que la chèvre effectue de 7 à 14 périodes de sommeil paradoxal survenant toujours après le sommeil lent, ce qui est en accord avec les travaux antérieurs de Ruckebusch. De même, la rumination est souvent suivie d'une période de sommeil lent et de sommeil paradoxal et elle est souvent contemporaine d'un état d'assoupissement.

2.2.3. Rôles d'autres structures cérébrales. - Comme chez les monogastriques, il doit exister des modulations quantitatives ou qualitatives de la prise alimentaire commandées par d'autres structures nerveuses. Très peu de travaux en neurochirurgie onf été effectués chez les ruminants. Des expériences consacrées à l'étude des lobectomies orbitofrontales chez la chèvre montrent une perturbation de la rumination.

En ce qui concerne le rôle des systèmes sensoriels dans l'initiation ou la modulation de la prise alimentaire, il y a extrêmement peu de travaux effectués en physiologie. Certes, les choix alimentaires en fonction des odeurs ou des sapidités ont été étudiés de façon très partielle par les nutritionnistes chez les ruminants. Pourtant, des expériences de conditionnement opérant, utilisant la prise alimentaire comme test, réalisées chez le mouton par Baldwin et Meese (1977) démontrent que les ruminants sont capables de discriminer très finement les odeurs. Le rôle de l'olfaction a surtout été étudié en relation avec le comportement sexuel depuis les travaux de Le Magnen (1952) chez le rat blanc et de Lindsay (1965) chez le bélier. Mais très peu d'études ont été réalisées sur les rôles de l'olfaction sur la prise de l'aliment chez les ruminants. En fait, il s'agit d'expériences mettant en relation i'olfaction et la gustation. En 1967, Greenhalgh et Reid démontrent que le mouton présente des appétits variables pour les différents aliments. Afin de minimiser le rôle de l'énergie ou l'encombrement apporté par l'aliment sur la quantité totale ingérée, les moutons sont munis d'une fistule du rumen par laquelle il est possible d'introduire les aliments. L'expérience se déroule comme suit : 1) le mouton dispose uniquement de la paille ef le foin est introduit dans l'estomac ; 2) l'animal ingère uniquement du foin et on introduit la paille dans l'estomac. A digestibilité égale entre les deux régimes, la paille moins appétente est moins consommée que le foin. Le rôle de l'olfaction et de la gustation est également bien mis en évidence par Baile et Martin (1971) qui démontrent chez la chèvre que certains condiments peuvent se montrer répulsifs (c'est le cas de la quinine, de l'acide acétique ou du chlorure de sodium). Il s'agit bien d'un effet sensoriel puisqu'une anesthésie locale fait disparaître cet effet néfaste. Toutefois, et en particulier pour certains aliments comme les ensilages, une faible concentration en acide acétique peut être un facteur améliorant la palatabilité (Goatcher et Church, 1970). De Vuyst et al. (1974) étudiant la consommation spontanée par le mouton de régimes enrichis en acide acétique ou en acétate démontrent que si on ajoute 4 p. 100 d'acide acétique, la consommation moyenne du

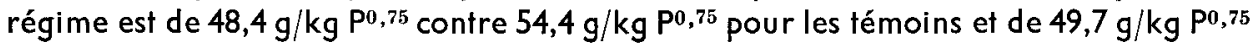
avec 4 p. 100 d'acétate.

Le ruminant en liberté choisit ses aliments, en refuse d'autres ou montre simplement de l'indifférence. Lorsqu'il n'y a pas de choix (ruminants à l'étable), il traduit son appétit selon Jarrige (1978) par sa vitesse d'ingestion ; « il entre une part d'inappétabilité dans la consommation très lente des fourrages pauvres (Greenhalgh et Reid, 1971) qu'on peut atténuer par l'imprégnation de mélasse, et, sans doute une part de grande appétabilité dans la consommation très rapide des fourrages condensés. 
Cependant, il est souvent très difficile de faire la part respective de l'encombrement et de l'appétabilité. » Jarrige met ici l'accent sur un problème effectivement difficile à résoudre. Il est relativement facile de supprimer l'olfaction par bulbectomie bilatérale bien qu'il soit difficile de dire si l'animal sent encore. Par contre, il est impossible d'abolir la gusfation ; on peut à la rigueur anesthésier les récepteurs du goût mais on anesthésie aussi les mécanorécepteurs permettant le réflexe de mastication, ce qui perturbe l'ingestion. Pour détruire l'olfaction ou la gustation et tester l'efficacité de l'opération il faudrait tout d'abord conditionner l'animal à une odeur ou à un goût précis et s'assurer de la disparition du conditionnement après l'intervention chirurgicale.

lggo et Leek (1967b) chez le mouton ont montré que les bourgeons du goût sensibles au salé et à l'acide envoient leurs afférences par le nerf corde du tympan ; l'amer et le sucré (et l'acide et le salé) sont relayés par le glossopharyngien. Des enregistrements électrophysiologiques de ces nerfs chez le veau (Bernard, 1964) ne permettent pas d'établir de relation entre les activités électriques des axones et les goûts ressentis par le veau. L'étude des relais centraux de la gustation chez les ruminants est limitée à quelques expériences de Larsson (1954) qui indiquent que la destruction du noyau thalamique ventral abolit l'aversion de la chèvre pour des solutions désagréables. A l'inverse, la stimulation stéréotaxique itérative de cette structure se traduit souvent par un comportement oral qui paraît être de dégoût.

En conclusion, nous pouvons dire que l'olfaction et la gustation sont peu connues chez les ruminants, mais que ces deux sensations interviennent efficacement pour le choix alimentaire et pour le rassasiement à court terme. A ce sujet, des ruminants porteurs de fistule œsophagienne chez qui, par conséquent, les aliments tombent en dehors du rumen, voient leur temps de prise alimentaire augmenté et «pseudo-consomment » de plus grandes quantités (Campling et Balch, 1961). Ce fait tendrait à prouver que les facteurs oropharyngiens mis en route lors de l'ingestion ne sont pas responsables à eux seuls de l'apparition de la satiété, d'autant plus que le «by-pass » de ces facteurs par une alimentation partielle par la fistule du rumen, n'élimine pas une régulation efficace des quantités ingérées (Baile et Mayer, 1967).

\section{3. - Régulation du comportement alimentaire.}

\section{1. - Rôle de la réplétion du réticulo-rumen.}

Les ruminants comme les monogastriques ajustent leur ingestion alimentaire pour équilibrer leur balance énergétique lorsque les dépenses d'énergie sous forme de chaleur corporelle, d'exercice, de croissance ou de lactation sont modifiées. Toutefois, il arrive fréquemment que les ruminants alimentés exclusivement par des fourrages grossiers n'en ingèrent pas suffisamment pour assurer une production (de viande ou de lait) maximale. Leur balance énergétique est alors négative. Avec ce type d'aliment à faible densité calorique, l'ingestion est limitée par la capacité du tractus digestif et plus particulièrement par la réplétion du réticulo-rumen, elle-même influencée par la vitesse de transit réticulo-omasale des aliments, qui dépend de la vitesse de digestion microbienne dans le rumen et de la réduction des aliments en fines particules.

\subsubsection{Mise en évidence d'une réplétion réticulo-ruminale. - Le facteur principal}


déterminant la capacité du tractus digestif est la taille de l'animal. En effet, Conrad, Pratt ef Hibbs (1964) ont pu mettre en évidence la relation entre l'ingestion d'un aliment à faible digestibilité ef le poids vif de l'animal.

Les facteurs modifiant la capacité de la cavité abdominale influencent la prise alimentaire des fourrages grossiers. Pendant la gestation, l'encombrement provoqué par le développement du fœtus peut limiter l'ingestion. Des brebis recevant un ensilage de mauvaise qualité ( 54 p. 100 de digestibilité) ou de foin ( 60 p. 100 de digestibilité) montrent une diminution continue de l'ingestion à partir de la $9 \mathrm{e}$ semaine de gestation jusqu'à la parturition (Forbes et Boaz, 1965). La prise alimentaire de foins de bonne qualité ( 65 à 69 p. 100 de digestibilité) ne décroît qu'à partir de la 14e semaine de gestation, tandis que l'ingestion d'une ration à base de céréales ( 82 p. 100 de digestibilité) augmente jusqu'à la 16 e semaine de gestation (Forbes, 1970). De plus, l'ingestion de foin en fin de gestation est diminuée davantage chez les brebis à portée gémellaire que chez celles développant un seul fœius (Forbes, 1971).

Chez les animaux gras, les dépôts de graisse dans la cavité abdominale réduisent la capacité de celle-ci. Parallèlement, on observe une diminution de l'ingestion des fourrages par ces animaux (Forbes, 1969). Toutefois, cette réduction de prise alimentaire n'est pas nécessairement un effet de limitation physique, puisque l'ingestion de concentrés est aussi réduite chez les animaux gras sans que le rumen ne soit engorgé (Bines, Suzuki et Balch, 1969). Cependant, le fait que des vaches grasses ne mangent pas assez de foin pour maintenir leur poids vif, alors que des vaches maigres mangent assez du même foin pour gagner du poids, tend à prouver l'existence d'une limitation physique (Bines, 1971).

L'encombrement du fourrage caractérisé par sa densité énergétique (kilocalories par litre de fourrage) est donc de nature à limiter la prise d'aliments. De fait, l'augmentation de densité obtenue par le broyage préalable des foins fait progresser l'ingestion de 36 à 96 p. 100 (Jarrige, 1978).

La prise alimentaire des fourrages est-elle limitée par un encombrement intestinal ou par un engorgement au niveau des estomacs? Les travaux de Grovum et Phillips (1978) nous ont éclairé sur ce point : l'introduction d'une substance inerte dans la caillette, tout en doublant l'excrétion fécale, ne modifie pas l'ingestion de foin haché de luzerne chez le mouton. Nous pouvons donc affirmer qu'avec les rations fibreuses, l'ingestion est restreinte par l'encombrement des pré-estomacs, rumen et réseau, et elle dépend, dès lors, du temps de séjour des aliments dans ceux-ci.

Le rôle limitant de la contenance du rumen dans la consommation a été plus ou moins bien démontré expérimentalement. Rappelons d'abord que le volume du contenu du rumen est plus élevé à la fin du repas qu'au début, et ce, malgré l'élévation de la vitesse de vidange du rumen pendant ce temps de prise alimentaire (Phillipson et Ash, 1965 ; Reid et al., 1979).

En 1961, Campling et Balch vérifient que la réduction de la capacité volumique du réticulo-rumen chez la vache, à l'aide de ballons souples contenant 22 à 45 I d'eau, entraînait une diminution de la quantité de foin ingérée ; celle-ci est de $240 \mathrm{~g}$ pour 4,5 I d'eau. Ruckebusch et Marquet (1965) précisent que la réduction de 60 p. 100 de la capacité du sac réticulo-ruminal des jeunes ovins ne recevant que du foin grossier entraîne une augmentation de la fréquence des repas. Par ailleurs, chez des chèvres, 
des ballons remplis d'air introduits dans le rumen, sont au moins aussi efficaces que ceux remplis d'eau pour réduire l'ingestion. C'est donc le volume des ingesta dans le rumen plutôt que leur masse qui serait le facteur limitant de la prise alimentaire des fourrages à faible densité calorique (Baile, Mayer ef Mc Laughlin, 1969). Plus récemment Grovum (1979) a pu inhiber l'ingestion chez des moutons affamés par distension ou par simple stimulation tactile du réseau. La distension du réticulo-rumen et/ou le frottement de la paroi par les brins les plus grossiers des fourrages agiraient sur la prise alimentaire via des tensio-récepteurs mis en évidence par lggo et Leek (1970) dans la paroi ruminale. Anand et al. (1964) avaient déjà signalé, chez le chat, que la distension gastrique modifiait l'activité des neurones situés dans l'hypothalamus médian via le nerf vague.

3.1.2. Facteurs influençant la réplétion du sac réticulo-ruminal. — La durée de rétention des aliments dans les pré-estomacs est inversement proportionnelle au niveau d'ingestion volontaire des aliments. Elle est conditionnée par l'obligation d'une réduction en fines particules (en moyenne inférieures à $0,45 \mathrm{~mm}$ ), seules susceptibles de franchir l'orifice réticulo-omasal. Blaxter, Wainman et Wilson (1961) et Campling, Freer et Balch (1961) ont montré la relation inverse entre le temps de rétention et l'ingestion des fourrages par les moutons et les bovins. D'autre part, lorsque l'ingestion de la même luzerne déshydratée et agglomérée par des moutons passe de 400 à $1300 \mathrm{~g} /$ jour, la vitesse de transit est augmentée de 50 p. 100 (Grovum et Williams, 1977). Ces différents faits expérimentaux démontrent que si le niveau d'ingestion d'un aliment est influencé par le temps de rétention de ce dernier dans le rumen, la vitesse de transit peut être elle-même influencée par la prise alimentaire. Néanmoins, tous les facteurs influençant la vitesse de transit des aliments modifient l'encombrement des pré-estomacs et donc, la prise alimentaire. Certains sont liés à l'alimentation ; ce sont la digestibilité ef la présentation physique de l'aliment, d'autres sont inhérents à l'animal, telles la motricité des réservoirs gastriques, la digestion microbienne et la mastication.

3.1.2.1. La digestibilité de l'aliment. - Blaxter (1950) chez les bovins, et Blaxter, Wainman ef Wilson (1961) chez le mouton, observent une augmentation des quantités ingérées de fourrages longs lorsque la digestibilité apparente de leur énergie s'accroît de 38 à 70 p. 100. L'élévation de 1 p. 100 de digestibilité entraîne une augmentation de l'ingestion de $1,5 \mathrm{~g} / \mathrm{kg} \mathrm{P}^{0,75} / \mathrm{jour}$. L'ingestion par le mouton d'aliments agglomérés sous forme de pellets augmente lorsque l'énergie digestible par gramme s'accroît jusqu'à $2,5 \mathrm{kcal}$. Avec des rations contenant plus de $2,5 \mathrm{kcal} / \mathrm{g}$, la prise alimentaire de matière sèche diminue tandis que l'ingestion d'énergie digestible reste constante (Dinius et Baumgardt, 1970). Apparemment, la réplétion du rumen limite la prise alimentaire des moutons quand l'énergie digestible de la ration présentée sous forme de pellets est inférieure à $2,5 \mathrm{kcal} / \mathrm{g}$.

3.1.2.2. La présentation physique de l'aliment. - Les aliments broyés et agglomérés sont ingérés par les jeunes bovins en quantité beaucoup plus importante que les foins longs correspondants. En effet, le broyage préalable des fourrages grossiers augmente leur vitesse de transit à travers les pré-estomacs, d'autant plus efficacement que le fourrage d'origine est plus médiocre, que le broyage est plus poussé et que 
l'apport de concentrés complémentaires reste inférieur à 30 p. 100 (Campling et Freer, 1966 ; Journet et Hoden, 1968). Par contre, le broyage des fourrages, bien qu'il facilite l'attaque microbienne grâce à la forte augmentation de la surface du substrat, tend à abaisser la digestibilité en raison de l'abrègement du transit ruminal (Campling et Freer, 1966). On constate à cette occasion que si l'ingestibilité évolue dans le même sens que la digestibilité, elle en reste indépendante.

Le comportement des ovins ef bovins sans litière et recevant une ration exclusivement broyée-agglomérée est profondément modifié ; le temps passé à ingérer et surtout à ruminer diminue en même temps que la taille moyenne des particules alimentaires. La durée de rumination égale ou supérieure à 35 p. 100 du temps avec les fourrages hachés, tombe à 3 p. 100 avec les fourrages condensés après un broyage à la grille de $3 \mathrm{~mm}$ (Demarquilly et Andrieu, 1970). La motricité gastrique ef la biochimie du rumen sont aussi modifiées : l'amplitude et la fréquence des contractions ruminoréticulaires primaires sont réduites, le $\mathrm{pH}$ du rumen devient plus acide par une diminution de l'insalivation et une fermentation microbienne plus rapide, le rapport acide acétique/acide propionique est diminué (Blaxter et Graham, 1956).

On sait encore que les fourrages broyés provoquent souvent des ennuis digestifs (indigestions et météorismes) liés à une diminution de la rumination. Il est donc important de déterminer la taille moyenne des particules au-dessus de laquelle la rumination est pratiquement normale ( \pm 30 p. 100 du temps) : elle doit être supérieure ou égale à $0,8 \mathrm{~mm}$ pour les graminées, et à $1,2 \mathrm{~mm}$ pour les luzernes (Demarquilly et Andrieu, 1970). Toutefois, pour s'assurer un maximum de sécurité, il suffit de maintenir les ovins ou bovins sur litière de paille : l'ingestion de $100 \mathrm{~g}$ de fourrage grossier par une brebis de $50 \mathrm{~kg}$ peut élever son temps de rumination à 15 p. 100 du nycthémère (Ruckebusch, 1968).

D'autre part, le simple hachage fin des fourrages ensilés est profitable à leur ingestibilité (Murdoch, 1965), non seulement par l'amélioration de leur état de conservation et de leur facilité de préhension (Dulphy et Demarquilly, 1972), mais aussi par les effets propres à la réduction de la longueur des brins d'ensilage. Le hachage des fourrages ensilés longs, avant l'affouragement permet d'augmenter sa prise alimentaire de l'ordre de 20 p. 100 chez le mouton (Deswysen, Vanbelle et Focant, 1978).

3.1.2.3. La motricité gastrique. - La motricité réticulo-ruminale est responsable du transit des digesta. La vagotomie totale abolit l'activité rythmique normale du rumen et du réseau et en même temps la propulsion des digesta à travers l'orifice réticuloomasal (Duncan, 1953). Il est probable que le type et la fréquence des contractions du réseau et de l'orifice réticulo-omasal (ORO) soient en relation avec la vitesse de transit.

L'activité motrice du réticulo-rumen est comparable chez les bovins, ovins et caprins. Elle est contrôlée par un stimulus rythmique et périodique provenant du noyau dorsal du vague via la voie motrice efférente du vague (Iggo et Leek, 1967). Les expériences de distension des estomacs ef de stimulation nerveuse réalisées par Dussardier (1955) montrent que des influx sensitifs d'origine gastrique, arrivant continuellement au bulbe par la voie vagale, peuvent participer à la régulation du rythme des contractions des estomacs. Ce rythme étant fonction de la densité des influx sensitifs, c'est sans doute la raison pour laquelle il est influencé par la prise alimentaire, la rumination, l'état physique de la ration et la pression intra-ruminale. 
Shalk et Amadon (1928) ont montré que la prise alimentaire entraîne une élévation de la fréquence des contractions réticulo-ruminales chez les bovins (de 60 contractions/h au repos à 105 contractions/h pendant un repas). Chez le mouton, la fréquence des contractions par 10 min passe de 3 à 8 avant le repas, à 20-30 pendant l'ingestion des aliments mais elle dépend de la voracité de l'animal, c'est-à-dire de la rapidité des mouvements de mastication. De fait, la fréquence diminue progressivement au cours d'un repas parallèlement à la vitesse d'ingestion (Le Bars, Nitescu et Simonnet, 1953a).

La motricité du complexe gastrique est fortement influencée par l'état physique du régime, l'augmentation de la fréquence ou de la force des contractions du sac rumino-réticulaire accompagnant un état plus grossier des aliments. Dans le cas de foin broyé, le nombre de contractions est toujours inférieur à celui enregistré dans le cas de foin long (Ruckebusch, 1967). La plus grande motricité enregistrée avec les fourrages grossiers est probablement causée par leur action sur les tensio-récepteurs à bas seuil de tension, mis en évidence par Harding et Leek (1972) dans la paroi médiane du réseau et dans le sac cranial du rumen. Louvier ef al. (1979) précisent que des pressions intraruminales inférieures à $10 \mathrm{~cm}$ d'eau augmentent la fréquence des contractions primaires par une action probable sur ces récepteurs à bas seuil de tension, tandis que des pressions supérieures à $10 \mathrm{~cm}$ d'eau inhibent les contractions primaires par excitation des récepteurs à haut seuil de tension mis en évidence dans le réticulo-rumen par Harding et Leek (1972). Dussardier (1955) avait déjà étudié ce double niveau de stimulation en distendant plus ou moins le réseau à l'aide d'un ballon rempli d'eau.

La rumination s'accompagne, pour chaque cycle, de manifestations gastriques (extra-contraction) et respiratoires (inspiration forcée) particulières. L'extracontraction (durée moyenne de 3 à $4 \mathrm{~s}$ ) précède la contraction réticulaire biphasique normale $(4 \mathrm{à} 5 \mathrm{~s})$ de telle sorte que l'ensemble des phénomènes moteurs du réseau dure près de $9 \mathrm{~s}$ lorsque l'animal rumine. L'inspiration forcée, responsable d'un renforcement de l'aspiration thoracique, survient au moment même où l'extra-contraction atteint sa valeur maximale. La fréquence des contractions est accélérée dès le début de la période de rumination, et passe, par $10 \mathrm{~min}$, de 5-8 à 14-20, chez le mouton (Le Bars, Nitescu et Simonnet, 1953a).

3.1.2.4. La digestion microbienne dans le rumen. - La cellulolyse est l'élément de digestion microbienne le plus important car elle assure la dissolution chimique des éléments fibreux, et tout ce qui l'active a le double mérite d'améliorer l'ingestibilité en même temps que la digestibilité.

De nombreuses expériences dont celle de Campling, Freer et Balch (1962) ont montré que l'addition de petites quantités d'urée aux fourrages pauvres augmentait leur ingestion et leur digestibilité. II existe donc probablement une relation causale entre la vitesse de digestion de la cellulose et la prise alimentaire des fourrages.

Si l'azote stimule la multiplication et l'activité des bactéries cellulolytiques, les glucides, facilement fermentescibles, ajoutés sous forme de céréales, de betteraves ou de mélasse, en complément de fourrages (surtout si ces derniers sont peu azotés) tendent à freiner la cellulolyse car la microflore les fermente préférentiellement à la cellulose. Il en résulte une diminution de la digestibilité et du niveau de consommation des fourrages. 
L'ensemble des minéraux esi également nécessaire car c'est tout l'équilibre alimentaire qui contribue à accélérer la cellulolyse microbienne et, par-là à accroître l'ingestibilité en même temps que la digestibilité des rations fourragères, améliorant ainsi doublement les apports nutritifs (Wolter, 1978).

3.1.2.5. La mastication. - Le facteur principal responsable de la réduction des particules alimentaires jusqu'à une taille suffisamment petite pour passer au travers de l'orifice réticulo-omasal est sans doute la mastication lors de l'ingestion et de la rumination. L'importance du broyage des aliments est suggérée par la relation directe existant entre le temps total de mastication par kilogramme de fourrage ingéré et la vitesse de transit des digesta dans le réticulo-rumen (Campling, Freer et Balch, 1962). Toute modification de l'efficacité de la mastication ( $p$. ex. à cause d'un défaut dentaire) par laquelle les petites particules capables de quitter le rumen sont produites, influence la vitesse de transit des aliments, donc le niveau d'ingestion.

Chez les ruminants recevant une alimentation de fourrages, la mastication mérycique est le facteur principal déterminant la vitesse de transit alimentaire dans le réticulo-rumen, et indirectement le niveau d'ingestion. Pearce et Moir (1964) empêchent des moutons de ruminer après un repas de fourrage en leur appliquant une muselière leur interdisant fout mouvement de mastication. Ils constatent chez ces animaux une augmentation du temps de rétention des digesta dans le tractus digestif, et une diminution de leur appétit. Ces deux constatations sont absentes lorsque l'animal ne peut ruminer après un repas de farine comme nous l'avons déjà signalé. Jean-Blain, Boivin et Bost (1971) ont montré que la rumination n'avait pas pour objet d'augmenter la digestibilité de la ration par sa réduction en fines particules, favorisant ainsi une attaque plus complète ef plus rapide par les micro-organismes du rumen, mais que le but essentiel du mérycisme était d'accélérer l'évacuation du sac réticuloruminal.

La fibrosité des ingesta est un facteur déterminant le nombre total de mouvements de mastication mérycique (Ruckebusch, Fargeas et Dumas, 1970). La durée de rumination, voisine de 30 p. 100 du nycthémère dans le cas de foin long chez les ovins, n'excède pas 8 p. 100 dans le cas de foin condensé à la suite d'une adaptation de 7 à 8 jours, puis 10 p. 100 au bout de 15 jours. La mastication à vide s'observe en effet chez le mouton recevant un aliment finement divisé à l'état de farine et chez la vache dans le cas d'une ration broyée-agglomérée. Elle correspond, dans ces cas, à une véritable adaptation au régime, vu que sa durée augmente progressivement du $4 \mathrm{e}$ au $10 \mathrm{e}$ jour.

Toutefois, la relation entre fibrosité des ingesta ef temps de rumination ne se vérifie pas toujours. Gordon (1958) constatait que ses moutons ruminaient plus longtemps lorsque le foin était haché que lorsque la même quantité de foin était donnée longue. L'ingestion d'ensilage long par des moutons provoque par rapport aux ensilages hachés, un plus grand temps de latence (période séparant la fin du repas principal el la première période de rumination), une diminution de la durée journalière de rumination et un grand nombre de cycles de pseudorumination (cycle mérycique caractérisé par un petit nombre de coups de mâchoire ef par un allongement des intercycles) (Deswysen, Vanbelle et Focant, 1978). Cet entravement de la rumination observé chez des animaux recevant des fourrages longs a été explicité par une étude 
cinéradiographique réalisée par Deswysen et Ehrlein (1979). Par l'ingestion d'ensilage long au lieu d'ensilage haché, les particules présentes dans le réticulo-rumen sont plus longues et entrelacées. Ceci provoque un retard de la migration des petites particules du sac ventral du rumen vers le sac cranial : pendant la période suivant le repas, il n'y a pas suffisamment de petites particules alimentaires présentes dans le réseau et dans le sac cranial du rumen dans lesquels la plupart des zones réflexogènes pour la rumination sont localisées (Iggo et Leek, 1970). Le mérycisme est ainsi retardé par l'ingestion de fourrages longs et est composé principalement de pseudorumination dans un premier temps.

L'encombrement de la ration est donc un facteur important dans le déterminisme du comportement alimentaire des ruminants. Toutefois, d'autres facteurs que la réplétion réticulo-ruminale peuvent contrôler simultanément la prise alimentaire des fourrages. Si des chèvres d'environ $30 \mathrm{~kg}$, à jeûn depuis $24 \mathrm{~h}$, reçoivent du foin ad libitum, elles en ingèrent $300 \mathrm{~g}$, alors qu'elles sont apparemment rassasiées par le repas de foin, de suite après celui-ci, elles peuvent encore manger $1 \mathrm{~kg}$ d'orge (Focant, 1979) ! Ce fait expérimental confirme les résultats de Greenhalgh et Reid (1971) qui établissaient l'importance des effets de l'appétabilité et des facteurs oropharyngiens dans l'ingestion des fourrages par le mouton.

\section{2. - Contrôle humoral de la prise alimentaire.}

Lorsque le ruminant reçoit une ration suffisamment concentrée sous forme d'aliments broyés et agglomérés, le repas n'est pas limité par un encombrement gastrique. C'est la consommation d'énergie qui est contrôlée par un ou plusieurs facteurs humoraux ou nerveux. Montgomery et Baumgardt (1965) observent chez des bovins, une diminution de l'ingestion journalière de matière sèche d'un aliment concentré lorsque la concentration énergétique augmente dans la ration. De la sorte, l'ingestion d'énergie reste constante. Seoane, Baile et Martin (1972) mettent en évidence l'existence d'un ou plusieurs facteurs humoraux modifiant le comportement alimentaire du mouton, par circulation croisée entre animaux affamés el rassasiés. Pendant l'heure de circulation croisée ef les 15 min suivantes, la consommation d'aliments concentrés des moutons rassasiés a augmenté de 48 p. 100 et la prise alimentaire des moutons affamés a diminué de 17 p. 100.

L'existence dans le sang de facteurs rassasiants nous fera rechercher les différents métabolites sanguins en relation avec la prise alimentaire.

Des travaux récents (Chase, Wangsness et Martin, 1977 ; Tindal ef al., 1978) ont l'avantage d'étudier un grand nombre de paramètres sanguins (glucose, AGV, AGL, insuline, $\mathrm{GH}$, prolactine...) dans le même temps. Ce procédé permet de vérifier les relations existant entre les différents métabolites. Le travail de Tindal nous révèle que les taux sanguins (veine jugulaire) de prolactine, d'hormone de croissance et d'insuline peuvent varier dans de grandes proportions au cours du nycthémère, chez la chèvre alimentée ad libitum de foin et de céréales. Toutefois, comme nous l'avons déjà souligné aucune variation de ces hormones n'a pu être mise en relation avec la prise alimentaire. Il en est de même des taux de glucose ef d'acides gras libres (AGL). Mais Manns et Boda (1967) insistaient sur la nécessité de l'étude des facteurs humoraux à partir de la veine porte car à ce niveau, ils n'ont pas encore été métabolisés par le 
foie, et les modifications de concentration apparaissent plus clairement. C'est probablement la raison pour laquelle Chase, Wangsness ef Martin (1977) enregistrent des variations du taux portal d'insuline, d'AGL, de glucose et d'AGV en relation avec l'ingestion d'un aliment concentré distribué ad libitum à des génisses Holstein. Le taux d'insuline plasmatique augmente dans les 2 min suivant le début du repas. Les AGL augmentent rapidement aussi, dès la $8^{\mathrm{e}}$ min d'ingestion, tandis que Decaen ef Journet (1967) enregistraient une forte diminution du taux d'AGL pendant les repas chez des vaches laitières! Le taux de glucose diminue après le repas qui dure environ $15 \mathrm{~min}$ ef augmente $60 \mathrm{~min}$ après. Ross et Kitts (1973) observaient par contre une augmentation de la concentration plasmatique de glucose après le repas chez des moutons. Personnellement, chez des chèvres alimentées de foin ou d'orge, nous avons toujours enregistré une glycémie indépendante des prises alimentaires et des périodes de rumination (Focant, 1979).

Toujours selon les travaux de Chase, Wangsness et Martin (1977), les concentrations d'acétate ef de propionate ne seraient pas modifiées par les repas tandis que le $\beta$-hydroxy-butyrate plasmatique augmenterait dans les $12 \mathrm{~min}$ suivant le début du repas, ef le butyrate dans les 16 min !. Ces résultats sont en opposition avec ceux de nombreux travaux réalisés depuis près de 20 ans. Déjà en 1962, Bensadoun, Paladines ef Reid mettaient en évidence l'augmentation régulière de l'absorption des acides gras volatils après l'ingestion de $1 \mathrm{~kg}$ de foin par un mouton. D'autre part, chez des bouvillons de 100 à $300 \mathrm{~kg}$, recevant des fourrages ad libitum, les taux d'acétate et de propionate sont plus élevés à la fin des repas qu'en début (Little et Hawkins, 1963). De même, lorsque des génisses sont entraînées à ingérer leur ration journalière de concentrés en un repas de 3 à 4 h, la concentration d'acétate esł maximale dans le sang à la fin du repas. Ce pic coïncide avec les teneurs maximales en AGV dans le jus de rumen (Baumgardt et al., 1964). Ces constatations sont confirmées par Simkins, Suttie et Baumgardt (1965a ef b) qui, de plus, signalent que la différence artério-veineuse d'acétate passe de 1 à $3 \mathrm{mg}$ par $100 \mathrm{ml}$ de sang du début à la fin du repas, chez la chèvre. Des prises de sang continues réalisées sur des chèvres, pendant des repas de foin ef d'orge et pendant des périodes de rumination, nous ont permis de mettre en évidence une élévation du taux plasmatique d'acétate dès le début des repas. Cetfe augmentation se poursuit pendant les $3 \mathrm{~h}$ suivant le repas et est d'autant plus importante que la quantité d'aliment ingérée a été plus grande. Le taux de propionate n'a été augmenté qu'après l'ingestion de grandes quantités d'orge. La concentration de butyrate dans le sang au niveau de la veine jugulaire est trop faible pour être mesurée de manière précise (Focant, 1979).

Comment expliquer l'augmentation rapide du taux sanguin des AGV? La concentration d'acétate est augmentée 5 min après le début du repas alors qu'à ce moment, peu d'aliment frais est arrivé dans le rumen et que la dégradation microbienne doit encore être insignifiante. Il est probable que cette élévation de la teneur en AGV dans le sang est la conséquence d'une plus grande absorption des AGV présents dans le rumen, au début du repas. Cet accroissement d'absorption serait causée par l'accélération de la fréquence des contractions du sac réticulo-ruminal enregistrée pendant les repas. Il est aussi possible que l'élévation du taux d'insuline pendant le repas soit provoquée par l'augmentation de l'absorption du propionate ef du butyrate. Manns 
et Boda (1967) chez le mouton et De Jong (1979) chez la chèvre ont en effet observé une augmentation des teneurs en insuline, glucagon et glucose, à la suite d'injections intraveineuses de propionate, de butyrate et de valérate. Par contre, des injections d'acétate et de $\beta$-hydroxy-butyrate sont sans effet sur la sécrétion d'insuline.

L'aminoacidémie des ruminants varie peu en fonction des apports protidiques alimentaires car la majeure partie de ceux-ci est dégradée par la flore du rumen.

Les ruminants ont une action dynamique spécifique (ADS) élevée, provenant de leur alimentation (Blaxter, 1962) ; la plus grande proportion est due aux fermentations microbiennes du rumen (Dale, Stewart et Brody, 1954). Différents travaux ont montré que la température du sang et de la peau augmente pendant le repas chez des bovins (Ingram et Whittow, 1962), chez le mouton (Mendel et Raghavan, 1964) et chez la chèvre (Baile et Mayer, 1968). Toutefois, la température hypothalamique s'accroît chez des chèvres ou des moutons à l'heure habituelle à laquelle le repas est offert, même sans distribution de l'aliment (Dinius, Kavanaugh et Baumgardt, 1970). Par contre, une alimentation intraruminale n'a pas d'effet sur la température hypothalamique (Baile et Mayer, 1968a). Il apparaît donc que le repas n'est pas la cause première de l'augmentation de la température hypothalamique ou périphérique chez les ruminants.

3.2.1. Théorie thermostatique. - Selon la théorie émise dès 1948 par Brobeck, les animaux mangent pour maintenir leur température et s'arrêtent de manger pour prévenir l'hyperthermie. Le principal argument sur lequel est fondée cette théorie est la stimulation de la consommation alimentaire lorsque l'organisme est exposé à une ambiance froide et son inhibition lorsqu'il lutte contre l'élévation thermique.

La satiété serait essentiellement produite par l'extra-chaleur liée à l'utilisation des nutriments (ADS). L'élévation thermique due à l'ADS agirait en tant que signal pour les thermo-récepteurs des centres hypothalamiques qui ajusteraient la consommation alimentaire en fonction de l'intensité des stimuli reçus.

La température relevée chez la chèvre par Baile et Mayer (1968c) au niveau de la région médiane de l'hypothalamus n'augmente pas au cours du repas. Si elle augmente, elle doit être attribuée à l'activité physique plus grande de l'animal au moment du repas et non pas à l'ADS (Dinius, Kavanaugh et Baumgardt, 1970). En effet, les animaux continuent souvent de manger après que la température cérébrale ait atteint son maximum et le temps mis pour retrouver le niveau de température antérieur au repas est souvent court et sans aucune corrélation avec l'importance ou la durée du repas. D'autre part, l'introduction dans le rumen d'un aliment ou d'acide acétique qui a pourtant une ADS élevée, n'entraîne pas d'élévation thermique au niveau hypothalamique (Baile et Mayer, 1968a).

L'ADS ne permet donc pas d'expliquer:l'apparition de la satiété. Cabanac (1979) le confirme : à court terme, la prise alimentaire n'est pas un comportement thermorégulateur.

Cependant la température peut être un signal pour la prise alimentaire et il n'est pas impossible que l'ADS puisse retarder l'apparition de la faim. Andersson et Larsson (1961) provoquent la consommation alimentaire chez la chèvre rassasiée par refroidissement de l'hypothalamus antérieur et de l'aire préoptique ; inversement, le réchauffement de la même zone inhibe le comportement alimentaire des 
chèvres affamées. Mais, les variations thermiques réalisées dans cette expérience sont importantes et s'éloignent des conditions physiologiques.

Bhattacharya et Warner (1968) introduisent dans le rumen de leurs vaches, pendant une période de $6 \mathrm{~h}$ d'alimentation, de grandes quantités d'eau froide ou d'eau chaude qui affectent la température tympanique d'environ $1{ }^{\circ} \mathrm{C}$. L'ingestion d'une ration de pellets est augmentée de 25 p. 100 par l'eau froide et est diminuée de 10 p. 100 par l'eau chaude.

De même, des changements de la température ambiante peuvent influencer la prise alimentaire. Des conditions climatiques chaudes ou froides affectent énormément le comportement alimentaire. Westra et Christopherson (1976) ont montré qu'une diminution de température environnante pouvait accélérer le rythme des contractions réticulaires, et le transit alimentaire. L'effet stimulant du froid sur l'appétit pourrait être une conséquence directe des effets de la température sur la vitesse de transit des aliments ingérés.

De plus, la plupart des maladies s'accompagnent d'une élévation anormale de la température corporelle (ou fièvre). Or, en général, les premiers symptômes observés chez l'animal malade sont dans l'ordre : l'arrêt de la rumination et la perte d'appétit. Van Miert (1971) a montré que l'injection d'endotoxines chez la chèvre induit la fièvre et en même temps inhibe la motricité réticulo-ruminale.

La régulation thermostatique de la prise alimentaire se limiterait-elle à une action de la température sur la motricité gastrique?

3.2.2. Théorie glucostatique. - La glycémie est considérée comme un facteur contrôlant le comportement alimentaire des animaux monogastriques. L'état de faim se produirait lorsque la différence artério-veineuse de la glycémie ( $\Delta$-glucose) tend vers zéro, c'est-à-dire lorsque la quantité de glucose utilisable par l'organisme tend vers zéro ; inversément la satiété correspondrait à une élévation du $\Delta$-glucose (Mayer, 1955). La théorie de Mayer a été confirmée par la mise en évidence des effets du 2 désoxy-D-glucose (2DG) sur la prise alimentaire. La molécule de 2DG vient, au niveau cellulaire, bloquer par compétition l'utilisation de la molécule de glucose. L'injection de 2DG établit donc une glucoprivation cellulaire et déclenche sans latence, la consommation d'aliments, puisqu'elle entraîne un abaissement du $\Delta$-glucose (Smith et Epstein, 1969).

L'emploi de l'aurothioglucose (ATG), molécule qui détruit les cellules ayant une affinité pour le glucose, a permis de mettre en évidence la présence de cellules glucoréceptrices dans les noyaux ventromédians et latéraux de l'hypothalamus (Smith, 1972). L'absence de fixation de l'ATG par le VMH chez la souris en diabète alloxanique, ou après l'injection d'un sérum anti-insuline, montre l'importance de l'insuline dans le fonctionnement des glucorécepteurs du VMH (Debons, 1968). L'insuline libérée par la simple présence de nourriture dans l'estomac ou au début de la lipogenèse après la prise de nourriture (Russek, 1971), agirait en facilitant le transport du glucose dans les récepteurs de satiété ventromédians (Le Magnen, 1969).

Par ailleurs, Russek (1970) a pu mettre en évidence un mécanisme hépatique glucosensible. Une injection de glucose dans la veine porte chez des chiens à jeûn entraîne une anorexie spectaculaire; dans les mêmes conditions une injection de glucose dans la veine jugulaire n'entraîne aucune anorexie. Toutefois, l'insuline est 
indispensable pour que le glucose produise son effet inhibiteur : l'injection intrapéritonéale de glucose chez le rat diabétique n'entraîne pas d'anorexie (Booth, 1972).

Chez les ruminants, la régulation glucostatique ne semble pas devoir jouer un rôle important. Dans des conditions physiologiques, nous avons vu que le taux de glucose ne variait pas en fonction des repas. Des injections intraveineuses de glucose avant ou pendant un repas ne modifient pas la prise alimentaire des bovins (Dowden et Jacobson, 1960), des moutons (Manning et al., 1959 ; Ulyatt, 1965) ou des chèvres (Baile et al., 1970). Des injections de solutions hypertoniques de glucose dans le liquide cérébro-spinal chez des chèvres (Baile et Mahoney, 1967), chez des moutons (Seoane ef Baile, 1972) et chez des veaux (Peterson, Baumgardt et Baile, 1971) augmentent l'ingestion, contrairement à l'inhibition de la prise alimentaire observée chez des rats après injection de glucose dans le ventricule latéral (Herberg, 1960). Ni la chèvre (Baile et Mayer, 1968b), ni le mouton (Baile et Martin, 1971) ne répondent par une ingestion accrue à une hypoglycémie induite par l'insuline. La glucoprivation ne semble donc pas stimuler la consommation alimentaire.

Dans leur recherche de glucorécepteurs centraux, Baile et al. (1970) n'obtiennent ni lésion hypothalamique, ni hyperphagie par injection intracarotidienne de fortes doses d'aurothioglucose à des chèvres et à des moutons. Seoane et Baile (1972) ont constaté que l'injection de 2-désoxy-D-glucose dans le $3^{\text {e }}$ ventricule du mouton augmente rapidement la prise alimentaire mais des résultats identiques sont obtenus avec le xylose et la réponse semble en rapport avec l'hyperosmolarité du liquide céphalorachidien. Houpt et Hance (1969) ont constaté chez la chèvre que des perfusions de 2DG pouvaient augmenter la prise de nourriture. L'injection d'aurothioglucose dans les ventricules latéraux du cerveau a entraîné chez le mouton une hyperglycémie semblable à celle observée chez les souris traitées par l'ATG. Ces résultats semblent indiquer, chez les petits ruminants, la présence de glucorécepteurs centraux susceptibles d'influencer la régulation de la glycémie et le comportement alimentaire, d'autant plus que Babapour et Bost (1973) observent une baisse de l'ingestion lorsque des injections de glucose dans les ventricules cérébraux sont accompagnées d'insuline. Les résultats de Houpt (1974) vont dans le même sens : l'insuline pourrait augmenter l'ingestion des ruminants. Tout récemment, Nicholson (1979) observe une augmentation de la vitesse d'ingestion d'une ration de foin chez des moutons après injection sous-cutanée de 2 UI d'insuline par $\mathrm{kg}$ de poids vif. Comment expliquer l'élévation de l'insulinémie pendant le repas ? Même la mise en évidence de glucorécepteurs n'implique pas nécessairement que, dans des conditions physiologiques, la prise alimentaire soit contrôlée par une régulation glucostatique.

Il ne semble pas exister chez le ruminant de glucorécepteurs hépatiques semblables à ceux mis en évidence par Russek (1970). Des injections de glucose dans la veine porte n'ont pas d'effet sur la consommation alimentaire de la chèvre ou du mouton (Baile et al., 1970). Ceci n'est pas étonnant si l'on sait que le glucose n'est pas un produit important de la digestion chez les ruminants : nous avons vu au chapitre 2.1 que la majeure partie des glucides est transformée en AGV dans le sac réticulo-ruminal par les micro-organismes. De plus, la glucokinase étant peu abondante joue un rôle physiologique négligeable.

Les relations entre la glycémie et la motricité des réservoirs gastriques chez le 
mouton ont été mises en évidence par Le Bars, Nitescu et Simonnet (1953b). Ces auteurs ont montré que l'hyperglycémie entraînait une diminution de la motricité tandis que l'hypoglycémie provoquait une augmentation de la motricité du rumen. Auclair (1962) confirme les corrélations étroites entre hypoglycémie et hypermotricité, et entre hyperglycémie et hypomotricité ; au cours de l'installation du diabète alloxanique chez le mouton; les modifications motrices affectent plus nettement l'amplitude des contractions que leur fréquence.

Par contre, Ali, Nicholson et Singleton (1976) observent une inhibition des contractions réticulo-ruminales ef abomasales après injection intraveineuse d'insuline entraînant une hypoglycémie. Cette inhibition pouvait être levée par la rumination, l'ingestion ou l'injection de glucose. Nicholson (1979) modifie, chez le mouton, le comportement mérycique par l'administration d'insuline. Le temps de rumination est diminué de 22 p. 100 pendant les 12 h suivant l'injection. Cette action est probablement causée par un certain degré d'inhibition de la motricité.

En conclusion, la glycémie est peu modifiée pendant les repas et dans des conditions normales, elle ne joue probablement pas un rôle important dans la régulation du comportement alimentaire des ruminants. Les résultats récents de Hikosaka, Sasaki ef Tsuda (1979) confirment ce point de vue puisque ni l'augmentation de la concentration de glucose ou d'insuline dans le plasma, ni l'hypoglycémie n'affectent la prise alimentaire à court terme, chez le mouton.

3.2.3. Rôle des acides gras volatils. - Chez les ruminants, une grande partie des apports énergétiques s'effectue par l'intermédiaire des acides gras volatils (AGV) produits par la microflore du rumen et absorbés à ce niveau. L'intensité de cette production est en relation avec l'ingestion d'aliments : elle est d'autant plus grande que l'aliment est plus énergétique. De surcroît, le fait que le taux sanguin d'AGV soit plus élevé à la fin des repas qu'au début et que la théorie glucostatique ait peu de chance d'intervenir dans le contrôle de la prise alimentaire, a conduit de nombreux auteurs à postuler l'intervention des AGV dans la régulation du comportement alimentaire.

Afin de vérifier cette hypothèse, de nombreuses perfusions intraruminales d'AGV ont été réalisées dans les années 60 chez des bovins (Rook, Balch et Campling, 1960 ; Montgomery, Schultz ef Baumgardt, 1963 ; Simkins, Suttie et Baumgardt, 1965 ; Bhattacharya et Warner, 1968), chez des moutons (Ulyatt, 1965 ; Baile et Pfander, 1966 ; Egan, 1966), et chez des chèvres (Baile et Mayer, 1967, 1968a, 1969 ; Baile et Mc Laughlin, 1970). II en ressort que chez chacune des espèces étudiées, l'injection d'acide acétique dans le rumen diminue l'ingestion alimentaire davantage que l'injection d'acide butyrique et d'acide propionique. Mais les AGV sont le plus souvent injectés isolément et en quantités importantes. II est probable que les conditions expérimentales modifient la biologie du rumen dans des proportions dépassant les limites physiologiques : Bhattacharya ef Warner (1968) réduisent de 40 p. 100 l'ingestion de foin chez des génisses par injection intraruminale d'1 $\mathrm{g}$ d'acétate $/ \mathrm{kg}$ de poids vif, avant le repas, tandis que les quantités ingérées ne sont pas modifiées par l'injection d'un mélange d'acétate et de propionate dans le rapport $5: 1$. De plus, il apparaît dans les expériences de Baile et Mayer $(1967,1968 a, 1969)$ que des perfusions d'acétate, de propionate ou de butyrate à la vitesse de 2,5 ou $5 \mathrm{mmoles} / \mathrm{min}$ (proches des 
productions dans le rumen) pendant les repas de chèvres nourries de concentrés ad libitum modifient peu la prise alimentaire.

L'étude approfondie du comportement montre que les injections intra-ruminales d'AGV réalisées chez des chèvres, pendant les repas diurnes de foin, ne sont pas suivies d'effet immédiat : les quantités ingérées pendant la période expérimentale ne sont pas modifiées (Focant et Gallouin, 1978). Par contre, le temps de rumination diurne est réduit de moitié et le repas d'orge offert le soir après l'arrêt des perfusions est réduit de plus ou moins 50 p. 100. L'absence d'une action rapide des AGV injectés dans le rumen permet de douter de la présence de chémo-récepteurs sensibles aux AGV au niveau gastrique.

Dowden et Jacobson (1960) ont montré qu'en perfusant chez des vaches laitières une quantité d'acide acétique ou d'acide propionique représentant 12,5 p. 100 des besoins énergétiques, dans la veine jugulaire pendant une période de $8 \mathrm{~h}$, l'ingestion alimentaire est presque complètement inhibée. Par contre, Baile et Mayer (1968a) ne constatent pas d'inhibition de la prise d'aliments concentrés chez la chèvre en injectant de 4 à 16 mmoles d'acétate/min pendant les repas spontanés. Chez le mouton, les injections d'acétate dans la veine ruminale semblent plus efficace pour réduire l'ingestion que les injections dans la veine jugulaire (Baile, 1971).

L'inhibition de la prise alimentaire par les perfusions intraveineuses de propionate est plus importante lorsque celles-ci sont effectuées dans une veine ruminale ou la veine porte, plutôt que dans une veine jugulaire ou la carotide (Baile ef Mayer, 1969 ; Baile, 1971 ; Anil ef Forbes, 1977). Ceci laisse entrevoir l'existence de récepteurs sensibles au propionate situés peut-être au niveau du foie. Bien qu'il soit un précurseur du glucose, le propionate semble intervenir lui-même puisque nous avons vu que les injections intraveineuses de giucose dans la veine jugulaire comme dans la veine ruminale resient sans effet.

Par ailleurs, Dowden et Jacobson (1960) avaient déjà mis en évidence l'inefficacité du butyrate, du valérate et de l'hexanoate comme dépresseurs de l'ingestion.

L'ensemble de ces travaux démontrent l'intervention de l'acétate et du propionate dans le contrôle du comportement alimentaire. On est ainsi conduit à envisager l'existence de chémo-récepteurs. Ils ne se situeraient pas au niveau hypothalamique puisque Baile et Mahoney (1966) n'observent pas de diminution de l'ingestion d'aliments chez des chèvres affamées dont ils perfusent le $3^{\mathrm{e}}$ ventricule avec $50 \mathrm{mmoles}$ d'acétate de sodium. Pour Baile (1971) des récepteurs répondant à la concentration d'acétate seraient sifués dans la paroi du rumen, et d'autres, sensibles au propionate, seraient localisés au niveau des veines ruminales. Anil et Forbes (1977) situent plutôt les récepteurs de propionate dans le foie. Cette localisation permet mieux d'expliquer la réduction de prise alimentaire provoquée par des injections d'AGV dans la caillette (Baile et Mc Laughlin, 1970 ; Papas et Hatfield, 1978).

En comparant les effets provoqués par des perfusions intraruminales ( $4 \mathrm{mmoles} / \mathrm{min}$ ) et intraveineuses ( $2 \mathrm{mmoles} / \mathrm{min}$ ) d'un cocktail d'AGV (70 p. 100 acétate +20 p. 100 propionate +10 p. 100 butyrate) réalisées pendant les repas de foin ou pendant les périodes de rumination, nous avons constaté : 1) les AGV injectés dans le rumen n'ont pas d'effet rapide, l'ingestion ou la rumination ne sont diminuées qu'après un certain temps de latence ; 2) les AGV injectés dans la veine jugulaire 
bloquent rapidement (10 $\mathrm{min}$ ) aussi bien la rumination que la prise alimentaire, mais cette inhibition cesse environ 15 min après l'arrêt de la perfusion, et 3) l'arrêt de la prise alimentaire ou de la rumination provoqué par une élévation du taux sanguin d'AGV est toujours accompagné d'une inhibition de la motricité du rumen (Focant et Gallouin, 1978 ; Focant, Gallouin et Leclercq, 1979). Même si comme le suggérait Baile (1971) des chémo-récepteurs sont localisés dans l'aire ruminale, il n'est pas exclu que l'on en trouve d'autres dans la voie systémique. En fait, la réduction de prise alimentaire provoquée par des perfusions intraveineuses ou intraruminales d'AGV ne serait-elle pas le simple reflet d'une inhibition de la motricité réticuloruminale mise en évidence par Le Bars et al., (1954) et par Ash (1956) ? En tout cas, l'augmentation de la concentration plasmatique d'AGV ne semble pas provoquer à elle seule la satiété. Une élévation importante des taux sanguins d'acétate, de propionate et de butyrate avant le repas d'orge journalier ne réduit la prise alimentaire que de 33 p. 100 chez des chèvres adultes (Focant, 1979).

3.2.4. Infervention de l'acide lactique. - L'alimentation intensive des ruminants fait appel d'une part à des aliments tels que les céréales qui donnent naissance à des taux élevés d'acide lactique dans le rumen, et d'autre part à des aliments qui, par eux-mêmes, apportent beaucoup d'acide lactique : c'est le cas des ensilages. Or l'ingestion volontaire des ensilages directs est généralement très inférieure à celle des fourrages verts ef aussi des foins correspondants. De nombreux auteurs ont tenté d'élucider le rôle de l'acide lactique dans cette moindre prise alimentaire.

Dowden et Jacobson (1960) ont montré que la perfusion lente d'acide lactique par voie intraveineuse (jugulaire) pendant une période de 8 h n'entraîne aucune diminution de l'ingestion d'aliments ni dans la période de l'injection, ni dans les heures qui suivent.

Senel et Owen (1966) et Bhattacharya et Warner (1967) montrent que l'acide lactique administré directement dans le rumen peut diminuer l'ingestion alimentaire tandis que le lactate de sodium ou de calcium ne modifie pas la consommation, ou parfois l'augmente. L'effeł dépresseur observé n'est-il pas un effet du $\mathrm{pH}$ ? Une baisse du $\mathrm{pH}$ détermine une augmentation de l'absorpíion des AGV; ce sont ceux-ci qui déprimeraient la prise d'aliments.

Morgan et L'Estrange (1977) observent qu'une ration de granulés contenant jusqu'à 13 p. 100 d'acide lactique par rapport à la matière sèche, est aussi bien ingérée par des moułons qu'une ration témoin sans lactate. Par contre, les mêmes quantités d'acide lactique injectées dans le rumen en $24 \mathrm{~h}$ réduisent la prise alimentaire. Il est probable que lors de l'addition d'acide lactique à l'aliment, l'acidité est neutralisée par une plus grande sécrétion salivaire pendant l'ingestion, ce qui empêcherait une baisse trop importante du $\mathrm{pH}$ ruminal.

La teneur des ensilages en acide lactique ne serait donc pas le facteur principal limitant leur ingestion. Clancy, Wangsness et Baumgardt (1977) le démontrent : l'injection intraruminale de 2,25 I de jus d'ensilage d'herbe chez la brebis au moment du repas inhibe la prise alimentaire de foin pour une période de $1 \mathrm{~h} 30$ à $9 \mathrm{~h}$ et perturbe la motricité du rumen. Par contre, l'injection d'un jus synthétique contenant des AGV, du lactate, des carbohydrates solubles, de l'ammoniaque, des nitrites et des nitrates, et ayant un $\mathrm{pH}$ et une osmolarité identiques à ceux du jus d'ensilage 
ne réduit l'ingestion que de 40 p. 100 : c'est que d'autres facteurs, comme les amines, pourraient avoir contribué aux effets dépressifs du jus d'ensilage.

Bueno (1975) signale que la perfusion duodénale de $12 \mathrm{mmoles} / \mathrm{h}$ d'acide DLi lactique réduit l'ingestion de pellets de luzerne ou de concentrés de plus de 50 p. 100 , tandis que la perfusion intraruminale a peu d'effet. Récemment, Smith, Krishnamurt ef Kitts (1979) confirment que la motricité du rumen n'est pas influencée par l'introduction d'acide lactique par voie intraruminale ou intra-veineuse. En revanche, quand ils le perfusent dans le duodénum, ils observent une phase d'inhibition totale de l'actitivité myoélectrique du rumen qui est toutefois suivie d'une remontée rapide à des niveaux quasi normaux, même si la perfusion se poursuit. L'inhibition de la motricité réticulo-ruminale par acidose lactique pourrait donc être imputable à l'acide lactique pénétrant dans l'intestin.

De toutes ces expériences, il ressort que dans des conditions physiologiques, l'acide lactique produit dans le rumen ou apporté par l'aliment ne semble pas jouer un rôle important dans la régulation du comportement alimentaire des ruminants.

3.2.5. Intervention des acides gras libres. - C'est Kennedy en 1950 qui a suggéré que le mécanisme de la satiété assure l'équilibre entre la consommation alimentaire et la dépense d'énergie pour éviter qu'un éventuel excès d'aliments ingérés ne se transforme en graisses. Ce serait l'augmentation du taux des acides gras libres (AGL) plasmatiques survenant avec la privation d'aliments qui pourrait être le signal inducteur de la prise alimentaire (Kennedy, 1966). Toutefois, le taux d'AGL n'augmente pas uniquement lors de la mobilisation des graisses de dépôt, mais aussi avec l'ingestion (Simkins, Suttie et Beaumgardf, 1965a ; Chase, Wangsness et Martin, 1977).

Journet et Rémond (1976) observent chez la vache qu'un taux élevé d'AGL dans le plasma après la mise-bas correspond à une période de faible ingestion, et que la prise alimentaire n'augmente que lorsque la concentration d'AGL est diminuée aux environs de $300 \mu$ réq/l.

Est-ce le taux élevé d'AGL qui réduit l'ingestion, ou est-ce l'ingestion insuffisante qui entraîne une augmentation de la concentration sanguine d'AGL par mobilisation des lipides ? A ce jour, aucun fait expérimental ne permet de répondre clairement à cette double question.

3.2.6. Rôle de l'aminoacidémie. - Un déséquilibre en acides aminés entraîne une diminution de la prise alimentaire chez des rats endéans les quelques heures, aussi bien à cause d'un excès (Scharrer, Baile et Mayer, 1970) que d'une déficience (Harper, Benevenga et Wolhueter, 1970) d'un ou plusieurs acides aminés ; ce déséquilibre a été considéré comme un composant possible du système de contrôle du comportement alimentaire.

Le taux d'acides aminés plasmatiques chez le mouton décroît pendant quelques heures après un repas unique journalier, ef augmente ensuite jusqu'à un maximum, $24 \mathrm{~h}$ après le repas (Theurer, Woods et Poley, 1966). Chez le mouton encore, des injections intraveineuses de glycine, d'alanine ou de lysine diminuent la prise alimentaire de concentrés de 12 à 30 p. 100 (Baile et Martin, 1971).

En nous référant aux données expérimentales disponibles, il semble invraisemblable que le repas des ruminants soił directement affecté par une modification du 
taux plasmatique en acides aminés. II est par contre probable que la couverture des besoins en acides aminés ef leur équilibre soient des facteurs de la régulation à long terme du comportement alimentaire.

3.2.7. Rôle du pH du rumen. - L'alimentation peut influencer le $\mathrm{pH}$ du jus de rumen. Une chute du $\mathrm{pH}$ ruminal est observée avec l'ingestion d'une grande quantité d'aliments rapidement fermentescibles. Or l'acidité totale du contenu du rumen peut inhiber l'appétit : des infusions intraruminales d'acides minéraux (chlorhydrique, sulfurique, phosphorique) ou organiques (citrique, lactique) réduisent considérablement la prise alimentaire alors que leurs sels de sodium sont très peu efficaces (Bhattacharya et Warner, 1967 ; Morgan et L'Estrange, 1977).

On constate qu'une alimentation de foin sous forme moulue cause une chute du $\mathrm{pH}$ ruminal plus importante que l'ingestion de foin non moulu. La sécrétion salivaire, qui est proportionnelle à la durée de mastication, donc de l'ingestion et de la rumination, se trouve notablement réduite lors de l'utilisation de fourrages conditionnés ef de concentrés ; le pouvoir tampon du jus de rumen en est très amoindri alors même que la fermentescibilité de la ration est vivement accrue; de ce fait, la chute du pH intraruminal liée à l'accroissement de la production des AGV et de l'acide lactique, est accélérée et accentuée à la suite des repas.

L'abaissement du $\mathrm{pH}$ du jus de rumen pourrait influencer le comportement alimentaire, en inhibant la motricité gastrique selon 2 modes d'action : d'une part en excitant des récepteurs sensibles aux modifications $\mathrm{du} \mathrm{pH}$, situés dans l'épithélium du rumen (Iggo ef Leek, 1967a), et d'autre part, en facilitant l'absorption des AGV par l'épithélium ruminal.

Toutefois, selon Baile et Forbes (1974), le $\mathrm{pH}$ des contenus du rumen n'interviendrait pas dans le contrôle du comportement alimentaire dans des conditions normales et physiologiques, mais il pourrait être la principale cause d'hypophagie dans certaines conditions pathologiques.

3.2.8. Intervention de la pression osmotique. - Chez le mouton, des augmentations de l'osmolarité du jus de rumen de 250 mosm. à 300-350 mosm. ont été observées pendant un repas important ingéré rapidement (Bergen, 1972) ; or une grande élévation de l'osmolarité du jus de rumen (jusqu'à 700 mosm.) induite par injection intraruminale de $\mathrm{NaCl}$ inhibe fortement la prise alimentaire. Par contre Kato, Sasaki ef Tsuda (1979), en injectant des solutions hypertoniques de polyéthylène glycol, $\mathrm{KCl}$ et $\mathrm{NaCl}$ dans le rumen pendant le repas, n'observent aucune corrélation entre la prise alimentaire et l'osmolarité du liquide du rumen, mais bien entre l'ingestion et les concentrations de sodium ef potassium.

En fait, les digesta ralentiraient la vitesse de vidange gastrique proportionnellement à l'effet osmotique réalisé sur les osmorécepteurs duodénaux (Gershon-Cohen, Shay ef Fels, 1938). Bell et Webber (1978) montrent que des solutions de bicarbonate de sodium ou de glucose injectées à raison de $500 \mathrm{~m}$-osmoles $/ \mathrm{kg}$ dans le duodénum de veaux engendrent une même vitesse d'évacuation d'un «test-meal ». Ce résultat est opposé à l'hypothèse émise par Hunt et Stubbs (1975) comme quoi ce serait la valeur énergétique des digesta et non leur osmolarité qui déterminerait la vidange gastrique. Mc Hugh ef Moran (1979) confirment chez le singe Maccaca mulata, les 
vues de Hunt et Stubbs (1975) : ils observent une diminution de la vitesse de vidange gastrique lorsque la concentration calorique augmente. Pour 2 solutions isotoniques ( $\pm 280 \mathrm{mosm} / \mathrm{kg}$ ) la vitesse de vidange est de $4,25 \mathrm{ml}$ avec le $\mathrm{NaCl}$ et de $1,81 \mathrm{ml}$ avec du glucose.

Ainsi, le mode d'action des récepteurs duodénaux est controversé, mais que ce soit l'osmolarité ou la concentration calorique qui soit déterminante, il n'en reste pas moins possible que ces récepteurs duodénaux jouent un rôle dans l'établissement de la satiété. En effet, Reid et al. (1979) ont montré chez le mouton alimenté de foin haché que 43 p. 100 de la vidange du rumen avait lieu pendant le repas $(4 \mathrm{~h})$; la quantité de digesta atteignant le duodénum durant cette période est donc importante.

Quoiqu'il en soit, le rôle des récepteurs duodénaux ne semble pas primordial : l'introduction d'aliments dans la caillette par une fistule abomasale ne réduit pas totalement la prise alimentaire orale de concentrés chez la chèvre, l'ingestion totale est même augmentée de 50 p. 100 (Baile ef Mayer, 1967).

\section{3. - Rôle des hormones digestives.}

Nous venons de mettre en évidence les relations existant entre les différents métabolites, les facteurs mécaniques et le comportement alimentaire. Nous avons vu également que beaucoup d'aliments subissent l'attaque des micro-organismes ; il en résulte une libération de nutriments (AGV) qui pénètrent dans l'organisme directement à travers l'épithélium du rumen. Mais les digesta franchissant l'orifice réticuloomasal subissent l'attaque des sécrétions digestives comme chez les monogastriques, et les nutriments obtenus sont absorbés par l'intestin grêle. Ces sécrétions digestives sont régulées par un ensemble d'hormones et de facteurs nerveux, et on s'est demandé s'ils ne pourraient pas jouer le rôle de facteurs de satiété.

Il est en effet intéressant de constater que la satiété apparaîf au moment où la régulation des sécrétions digestives s'établit. Par conséquent, chaque hormone digestive a été, a priori, considérée comme facteur de satiété possible et a été testée dans ce sens. C'est le cas de la gastrine, de la cholécystokinine, de la sécrétine, du polypeptide intestinal vasoactif (VIP), de la motiline, du polypeptide inhibiteur gastrointestinal (GIP). De plus, la cholécystokinine, la gastrine et le VIP ont été mis en évidence dans le tissu cérébral (Dockray, 1976 ; Rehfeld et Kruse-Larsen, 1978). A l'inverse, des facteurs connus seulement au niveau hypothalamique, ont été retrouvés à la périphérie de l'intestin : somatostatine, neurotensine et TRH (hormone de libération de la thyroxine). Il serait fastidieux de rapporter toutes les expériences réalisées sur ces différents facteurs, d'autant plus que très peu de travaux ont été, jusqu'ici, consacrés aux ruminants. Trois facteurs parmi ces hormones ont des effets certains au niveau de la régulation du comportement alimentaire : la cholécystokinine, l'entéroglucagon et peut-être la neurotensine.

Les premières expériences consacrées à l'étude du rôle possible de la cholécystokinine comme facteur de régulation de la prise alimentaire ont été conduites par Glick, Thomas et Mayer (1971). A la suite d'injections de CCK-PZ dans le système porte par voie intrapéritonéale, ces auteurs n'ont trouvé aucun effet sur la satiété du rat. Mais ces conclusions devaient être très rapidement et définitivement infirmées par la suite. 
En effet, Gibbs, Young et Smith (1973a et 1973b) ont testé les effets au niveau de la satiété, de la sécrétine et du glucagon ; ces hormones ne semblent avoir aucun effet rassasiant à court terme. Par contre, ces auteurs ont démontré chez le rat (1973) et chez le singe (Gibbs, Falasco ef Mc Hugh, 1976) que la cholécystokinine (CCK) produit une très puissante et rapide inhibition de la faim. Cette hormone agit exclusivement sur la satiété el semble dénuée d'effets sur la soif. De plus, Antin et al. (1975) ont démontré que la CCK, au même titre que les aliments contenus dans l'intestin, déclenche les séquences comportementales caractéristiques de la satiété, sans apparition de nausées. Kulkosky et al. (1976) ont montré que la CCK-OP était capable d'induire la satiété chez le rat rendu hyperphagique par lésion du noyau ventromédian. Ce fait serait donc en faveur de l'existence d'un effet direct du CCK-OP sur les centres de l'hypothalamus latéral (LH), puisque le noyau ventromédian n'est plus fonctionnel. Cette mise en évidence du rôle de la CCK dans les mécanismes de satiété est extrêmement importante ef a donné lieu à de nombreux travaux dans d'autres espèces, y compris les ruminants. Houpt, Anika ef Wolff (1978) ont retrouvé les mêmes résultats chez le lapin. Par contre, Snapir et Glick (1978) ne retrouvent pas l'effet rassasiant de CCK-OP chez la poule domestique. Très récemment, Bunnett ef Harrison (1979) ont mis en évidence la présence de cellules sécrétant la gastrine et la cholécystokinine dans la caillette et le duodénum du mouton. De plus, Della Fera et Baile (1979) ont pu obtenir le rassasiement chez le mouton, à la suite de l'injection dans le liquide céphalo-rachidien de l'octapeptide terminal de la cholécystokinine. La durée du rassasiement obtenu dépend de la dose de CCK-OP injectée. La pentagastrine supprime aussi l'ingestion alimentaire mais à une concentration très supérieure ( 1000 fois plus). Par contre, la sécrétine injectée de la même façon n'a pas d'effet rassasiant. Ces expériences suggèrent que la CCK joue un rôle physiologique dans la satiété, en agissant directement au niveau du cerveau mais elle possède aussi un effet sur la motricité des réservoirs gastriques qui se traduit par une baisse de la force des contractions. Il est probable que cette inhibition est le fait de la mise en jeu de centres nerveux supérieurs de commande de la motricité.

L'octapeptide terminal de la cholécystokinine (CCK-OP) n'est vraisemblablement pas l'hormone physiologique de la satiété. Très récemment, Knoll (1979) a mis en évidence une substance : la satiétine, capable de réduire la prise alimentaire de façon radicale chez le rat pendant $96 \mathrm{~h}$. La satiétine a éfé isolée du sérum humain et purifiée sur gel. Son poids moléculaire serait compris entre 40000 et 60000 . Cette substance exerce un effet anorexigène proportionnel à la dose injectée à la fois en injections intraveineuses ef intraventriculaires. L'octapeptide terminal de la sécrétine (CCK-OP) ef le peptide Glu-His-Gly-OH sont donc des substances capables de réduire l'ingestion chez les rongeurs et les ruminants, mais ils ont des effets rassasiants inférieurs à ceux de la satiétine.

La satiétine agirait directement sur les neurones de l'hypothalamus : l'utilisation d' $\alpha$-méthyl-tyrosine, qui, en se comportant comme faux précurseur de noradrénaline, bloque la transmission nerveuse au niveau du noyau ventromédian, est sans effet sur la satiétine. On manque encore d'expériences complémentaires confirmant cette découverte. Si elle se confirme, on aura réussi enfin, à mettre en évidence une hormone de la satiété.

Il est en outre vraisemblable que la CCK est douée d'autres propriétés physiolo- 
giques au niveau du cerveau. Dafny, Jacob et Jacobson (1975) ont montré que CCK-OP pouvait moduler l'activité neuronique de diverses parties du cerveau pendant la prise alimentaire. Cette hypothèse a pu être établie à la suite de l'enregistrement, chez des rats, de potentiels acoustiques évoqués dans l'hypothalamus ventromédian ef latéral, le noyau hypothalamique antérieur, le septum pellucidum, l'hyppocampe dorsal, le complexe amygdalien, les noyaux du raphé et le noyau caudé ; par contre, ni la pentagastrine, ni la sécrétine de synthèse ne modifient les potentiels évoqués par la stimulation acoustique, enregistrés dans ces huit structures cérébrales.

\section{4. - Rôle d'autres facteurs endocriniens.}

Nous avons précisé dans l'introduction consacrée à l'étude des rôles de l'hypothalamus, que cette structure diencéphalique pouvait être considérée comme un véritable carrefour nerveux ef endocrine, ou sphère d'exécution neuro-endocrinienne des comportements. II existe de multiples relations entre les différents comportements ; nous nous proposons de rapporter quelques interactions possibles entre les hormones sexuelles ef le comportement alimentaire.

3.4.1. Rôle des corticoïdes sexuels. - Il est bien connu que pendant la phase œstrale du cycle de l'ovaire, la femelle des animaux domestiques présente un comportement de recherche du mâle et que sa consommation alimentaire est généralement réduite. A cette période d'œstrus, le taux des œestrogènes libérés est maximum. On a donc recherché, depuis un certain nombre de décennies, les effets des œstrogènes au niveau hypothalamique, mais les relations entre les comportements sexuel et alimentaire n'ont été envisagées que depuis une époque récente.

Les travaux de Wade (1972) chez le rat, et ceux de Forbes (1972) chez le mouton et la chèvre ont permis de faire une remarque intéressante : les œstrogènes réduisent la prise alimentaire, mais l'effet dépend de la dose car, au contraire, à faible dose et à la suite d'une longue période d'administration, ils stimulent la croissance et l'ingestion chez les ruminants. Ceci ne doit pas nous étonner : la fonction de reproduction est essentiellement dominée par la variation temporelle du rapport existant entre les œstrogènes et la progestérone. Parfois, ces hormones agissent en synergie de succession (de la phase de maturation folliculaire à la phase lutéale), mais elles agissent aussi en synergie de simultanéité. Elles ont enfin des actions antagonistes ; il a été clairement démontré chez le rat que les injections de progestérone produisent une augmentation de la prise alimentaire (Hervey et Hervey, 1966 ; Wade et Zucker, 1970). Tout est une question de rapport entre les quantités d'œstrogène et de progestérone. Des expériences ont été conduites pour connaître les effets des œstrogènes. De façon à éviter un effet possible de la progestérone, Forbes (1974) a recherché les effets du benzoate d'œstradiol en administration intraventriculaire et en injection intraveineuse chez le mouton mâle castré. L'injection intraventriculaire de faibles quantités de benzoate d'œstradiol provoque une prise alimentaire immédiate (après $30 \mathrm{~min}$ ) alors que des quantités plus fortes injectées dans le liquide céphalorachidien ou par voie systémique dépriment la prise alimentaire. Dans le cas des injections par voie systémique, on sait que la période de vie de la molécule est brève et que celle-ci n'a peut-être pas le temps d'agir au niveau hypothalamique. La progestérone, en mélange avec l'œstrogène au niveau hypothalamique, abolit la prise alimentaire. Il y a donc, à ce niveau, et pour cet 
effet, un antagonisme entre les deux hormones. Il est probable que l'cstradiol agit par l'intermédiaire d'un mécanisme adrénergique, ou encore indirectement à travers la libération de l'hormone de croissance.

Dans la période prépartum, la consommation alimentaire décroît souvent, alors que le taux d'œstrogène augmente. Barbeloh, Hibbs et Conrad (1975) eurent l'idée d'augmenter la concentration en progestérone au niveau du plasma les derniers jours de la gestation, pour étudier les effets sur la prise alimentaire. Les vaches reçoivent, pendant les 15 jours précédant la date de la parturition présumée, 0,25 $\mathrm{mg}$ de progestérone par $\mathrm{kg}$ de poids vif. La consommation alimentaire augmente alors de façon significative. Cet effet de la progestérone, au niveau de l'organisme entier, peut être inversé par des injections d'œstradiol ou des administrations par voie orale d'acétate de mélengestrol. Cette expérience confirme donc en tous points celle de Forbes et fait encore apparaître l'antagonisme qui existe entre les œstrogènes et la progestérone, à certaines périodes de la vie physiologique de la femelle. On ne sait pas quelle est la signification précise de cette baisse de consommation chez la femelle en fin de gestation : il y a plus de raisons pour que la femelle mange davantage que l'inverse :1) c'est à la fin de la gestation que les besoins du fœtus sont les plus importants, 2) le cortisol fœital augmente vers le terme, ce qui induit, par passage de celui-ci à travers le placenta, une biogenèse accrue des œstrogènes maternels, or le cortisol est connu comme ayant des propriétés stimulantes de l'appétit. On peut penser que, peu de temps avant la mise-bas, le placenta devenant de moins en moins capable de transférer les nutriments de la mère au fœtus, ceux-ci s'accumulent exagérément au niveau maternel, et qu'ainsi la satiété apparaît.

Tout porte à croire cependant, car correspondant bien avec ce que l'on observe en pratique, que cet effet inhibiteur des œstrogènes sur la prise alimentaire est bien l'effet physiologique. Forbes observe une augmentation de la prise alimentaire avec de faibles doses d'œstrogènes dans l'hypothalamus ; or pendant les chaleurs (ou œstrus) le taux des œstrogènes est élevé : il y a baisse de la prise alimentaire.

Ruckebusch (1975) a étudié les relations entre la prise alimentaire de la vache et l'état de vigilance juste avant ef après la parturition. II constate que des perturbations de la prise alimentaire peuvent être observées en relation avec l'établissement de la lactation ou le sevrage. Ces observations laissent supposer que les hormones sexuelles ne sont pas les seuls facteurs capables de moduler le comportement alimentaire pendant ces périodes, mais que des facteurs « psychologiques» peuvent également intervenir.

Les androgènes au même titre que les œstrogènes ont un effet modérateur sur la prise alimentaire des ruminants. Ce fait est connu depuis la plus haute antiquité ; il était déjà établi que la castration se traduit par une élévation du poids corporel. Ce phénomène est en réalité le résultat d'effets multiples : calme des animaux, modifications métaboliques, augmentation de la prise d'aliments en rapport avec l'augmentation de la stature.

\subsubsection{Glucocorticoïdes.}

En ce qui concerne le rôle des corticoïdes surrénaliens dans la prise alimentaire chez les ruminants, il convient de signaler que les expériences semblent contradic- 
toires. Il a été démontré que l'injection intramusculaire de glucocorticoïdes chez le mouton pendant plusieurs semaines augmente la consommation alimentaire (Spurlock et Clegg, 1962), mais à condition que les moutons ne soient pas de gros mangeurs (Bassett, 1963).

Par contre, Baile et Martin (1971) ne retrouvent pas cet effet. Il est vrai que ces auteurs injectent l'hydrocortisone par voie intraveineuse pendant les repas spontanés de l'animal à des doses telles qu'elles multiplient par 1000 le taux des 17-hydroxycorticostéroïdes normalement présents chez le mouton. Il est possible que des quantités trop fortes de ces hormones produisent les effets inverses. II serait intéressant de reprendre ces expériences afin d'étudier les modifications produites sur la rumination. Il est possible que les effets soient plus nets.

Dans les conditions de la thérapeutique vétérinaire, il est bien classique de provoquer l'augmentation de l'appétit par l'injection de glucocorticoïdes (traitement de l'eczéma, par exemple). Il est vraisemblable, dans le cas de traitement par la voie générale, que les corticoïdes interviennent sur la prise alimentaire par l'intermédiaire du métabolisme énergétique. Les glucocorticoïdes ne jouent probablement qu'un faible rôle physiologique dans la prise alimentaire.

On a recherché les effets sur la prise de nourriture, des autres hormones à activité métabolique importante. Driver et Forbes (1978) ont démontré clairement chez le mouton, que la taille des repas augmente de façon significative à la suite de l'augmentation rapide de l'hormone de croissance $(\mathrm{GH})$. Mais cet effet n'est observable que si la concentration en acides gras disponibles libérés par la lipolyse vient à baisser. Ces auteurs constatent que la prise de nourriture spontanée se produit quand les taux plasmatiques de l'hormone de croissance sont faibles. De la même manière, Driver, Forbes et Scanes (1979) ont démontré que la libération de l'hormone de croissance, à la suite d'une injection ventriculaire de carbachol, produisait une baisse de la prise alimentaire. L'action rassasiante de l'hormone de croissance serait due à l'augmentation des acides gras libres au niveau du plasma ou à d'autres produits résultant de la lipolyse (théorie lipostatique). Cette interprétation nous semble logique, mais des résultats inverses ont pu être mis en évidence à la suite des travaux de Baile et Martin (1974a), qui trouvent que l'injection intraventriculaire de $10 \mu \mathrm{g}$ de carbamyl-choline (carbachol) stimule la prise alimentaire. Dans les deux expériences, les doses de carbachol, sont pourtant identiques. Les différences constatées ne sont pas encore explicables. Nous pensons qu'il serait intéressant de comparer les conditions expérimentales, et en particulier, les vitesses d'injection du carbachol utilisées par les deux laboratoires.

Dans ce même travail, Driver, Forbes ef Scanes (1979) ont encore pu montrer que les injections de noradrénaline, dopamine ou sérotonine dépriment les taux de prolactine circulante. De ce fait, et en accord avec les travaux de Baile et al. (1972), concernant l'effet inducteur de la prise alimentaire de la noradrénaline on peut dire que la prolactine a un effet dépresseur de l'ingestion au même titre que l'hormone de croissance.

Dans un récent travail, Tindal et al. (1978) ont étudié la libération spontanée de I'hormone de croissance chez la chèvre en lactation ou sevrée, en relation avec le comportement alimentaire, l'état de vigilance, la prolactine, l'insuline et la glycémie, et les acides gras libres sanguins. Ce travail très complet ne permet, malheureusement 
pas, d'établir de façon évidente une quelconque relation entre tous ces facteurs. Par contre, comme nous l'avons déjà rapporté dans un chapitre antérieur, il existe des relations évidentes entre la prise alimentaire, la rumination ef la vigilance. Cette expérience, bien que n'apportant pas d'éléments très positifs concernant l'ingestion chez les ruminants, est riche d'enseignements. Elle suggère que les facteurs qui ont été étudiés n'interviennent peut-être pas directement sur la prise alimentaire ; leurs métabolites intermédiaires seraient également à tester.

3.4.3. Rôle des hormones thyroïdiennes. - Andrews et Bullard (1940) ont constaté, chez les bouvillons partiellement thyroïdectomisés, une augmentation de poids dans les huit semaines qui suivent l'intervention. Par la suite, l'hypertrophie compensatrice du tissu glandulaire restant, fait que les animaux maigrissent ef reviennent à leur poids initial. En partie grâce aux travaux de Astwood (1943), on a pu isoler un certain nombre de substances à effet antithyroïdien. Il faut rappeler que la propriété antithyrö̈dienne (goitrigène) se rencontre dans des aliments naturels d'origine végétale ou animale (arachide, soja, crucifères, légumineuses...). En élevage, à cette époque, on avait tenté d'utiliser ces substances pour améliorer la vitesse d'engraissement. Depuis, elles ont été abandonnées ou interdites.

A l'opposé, une élévation de ces mêmes hormones : tétraïodothyronine (thyroxine) triiodothyronine, induit une hyperphagie chez le rat (Le Magnen et Tallon, 1967). L'hyperphagie se manifeste au début par une augmentation de la fréquence des repas, puis peu à peu, leur taille augmente et leur fréquence redevient normale. L'hyperphagie aboutit à une surconsommation de 50 p. 100 la nuit et de 20 à 25 p. 100 le jour, ce qui est considérable.

Des injections de thyroxine ont été réalisées chez le mouton depuis de nombreuses décennies. Elles ont permis de consfater que la réponse primaire à cette élévation du taux d'hormones thyroïdiennes, était une baisse de poids probablement due à une augmentation de la vitesse de transit (motricité gastrique et péristaltisme intestinal). Ensuite, l'ingestion est accrue dans la plupart des cas mais la baisse pondérale n'est pas toujours récupérable, car la thyroxine stimule également la mobilisation des dépôts énergétiques.

Ces données montrent que les ruminants peuvent ajuster leur prise alimentaire en fonction de leurs besoins énergétiques dus à des modifications des exigences métaboliques.

\section{4. - Conclusion.}

Au terme de cette revue bibliographique, limitée à l'étude des phénomènes directement liés à la prise alimentaire, nous pouvons faire les remarques suivantes.

Nos connaissances sont extrêmement pauvres en ce qui concerne l'influence des facteurs sensoriels au niveau de l'ingestion chez les ruminants. Il serait très intéressant de préciser les rôles de l'olfaction dans le choix alimentaire et dans la régulation quantitative de l'ingestion. Des additifs odorants ou «flaveurs » pourraient, sans doute, permettre d'augmenter la prise alimentaire ou de masquer certaines odeurs déplaisantes pour l'animal, et ainsi d'augmenter la palatabilité des aliments.

Les rôles de la vision et de la gustation sont de même très peu connus, bien que ces 
informations sensorielles interviennent certainement dans la reconnaissance de l'aliment et dans son choix.

Les centres cérébraux impliqués dans la régulation du comportement alimentaire chez les ruminants ont été étudiés par quelques équipes de chercheurs. Ce travail mériterait d'être poursuivi de façon systématique. Les recherches chez le rat sont en effet considérablement plus développées, mais il est difficile d'extrapoler les résultats chez les ruminants.

On a toujours tendance à minimiser le rôle de la glycémie comme facteur de rassasiement à court terme. Une étude précise du rôle exact de ce paramètre sanguin nous semble indispensable. La valeur absolue de la glycémie, bien que fluctuante, est cependant un paramètre assez stable chez les ruminants. La glycémie est beaucoup plus stable que le taux sanguin des acides gras volatils qui jouent pourtant un rôle énergétique fondamental.

En fait, à ce jour, aucun facteur sensoriel ou métabolique ne permet d'expliquer à lui seul les mécanismes de la faim ef de la satiété. Pourtant, la palatabilité de l'aliment, l'encombrement volumétrique du réticulo-rumen par la ration, la glycémie, l'insulinémie, les acides gras volatils du rumen et du sang, l'acide lactique, les acides gras libres sanguins, le pH du jus de rumen, la pression osmotique des bols alimentaires pénétrant dans le duodénum, ef certaines hormones digestives sont capables de modifier la prise alimentaire, la rumination ou la motricité des réservoirs gastriques. II est possible que la satiété soit le résultat de l'intégration de tous les influx nerveux arrivant au système nerveux central, et provoqués par l'action de ces facteurs sensoriels, métaboliques et humoraux sur des récepteurs spécifiques ou non, situés au niveau gastrique, intestinal, systémique ou central.

II reste encore, dans de nombreux domaines physiologiques, beaucoup de travail à accomplir. Mais si l'on veut réellement faire progresser la Science, il faut de plus en plus pousser les moyens d'investigation. La simple étude de la variation d'un paramètre, aussi important soit-il, n'est plus suffisante. Il devient indispensable d'établir de multiples corrélations temporelles entre de nombreuses variables. Les expériences sont donc lourdes et leur analyse ne peut se faire que grâce à la mise en œuvre de moyens de calculs de plus en plus sophistiqués. S'il est vrai qu'un scientifique de notre époque est spécialisé à outrance, ces recherches doivent être l'œuvre d'une équipe pluridisciplinaire.

Journées Ingestion-Digestion-Absorption de l'Association française de Nutrition, Paris, 15-16 novembre 1979.

\section{Références}

ALI T. M., NICHOLSON J., SINGLETON A. G., 1976. Stomach motility in insulin-treated sheep. Quart. J. exp. Physiol., 61, 321-329.

ANAND B. K., DUA S., SHOENBERG K., 1956. Hypothalamic control of food intake in cats and monkeys. J. Physiol., 127, 143.

ANAND B. K., CHINA G. S., SHARMA K. N., DUA S., SINGH B., 1964. Activity of single neurons in the hypothalamic feeding centers : effect of glucose. Am. J. Physiol., 207, 1146-1154.

ANDERSSON B., LARSSON B., 1961. Influence of local temperature changes in the preoptic area and rostral hypothalamus on the regulation of food and water intake. Acta physiol. scand., 52, 7589. 
ANDREWS F. N., BULLARD J. F., 1940. The effect of partial thyroidectomy on the fattening of steers. Amer. Soc. anim. Prod. Proc., 112-116.

ANIL M. H., FORBES J. M., 1977. Disruption of feeding behaviour in sheep by portal vein infusions of mixed volatile fatty acids or propionate. Proc. Nutr. Soc., 36, A 68.

ANTIN J., GIBBS J., HOLT J., YOUNG R. C., SMITH G. P., 1975. Cholecystokinin elicits the complefe behavioural sequence of satiety in rats. J. comp. physiol. Psychol., 89, 784-790.

ASH R. W., 1956. Inhibition of reticulo-rumen contractions by acid. J. Physiol. London, 133, 75P-76P.

ASTWOOD F. B., 1943. The chemical nature of compounds which inhibit the fonction of the thyroid gland. J. Pharmac. exper. Therap., 78, 79-89.

AUCLAIR M., 1962. Contribution à l'étude de l'influence de l'état humoral sur la motricité gastrique chez les petits ruminants. Th. Doct. vét., Paris.

AUFFRAY P., 1969. Effets des lésions des noyaux ventromédians hypothalamiques sur la prise alimentaire chez le porc. Ann. Biol, anim. Bioch. Bioph., 9, 513-526.

AUFFRAY P., BLUM J. C., 1970. Hyperphagie et stéatose hépatique chez l'oie après lésion du noyau ventromédian de l'hypothalamus. C. R. Acad. Sci. Paris, sér. D, 270, 2362-2365.

AUFFRAY P., GALLOUIN F., 1971. Obésité et hyperstéatose hépatique provoquée par injection de 6-hydroxy-dopamine au niveau du cerveau de l'oie. 10e Congr. mond. Zoofech., Versailles, 20-23 juillet, thème VII.

BABAPOUR V., BOST J., 1973. Action de l'aurothioglucose sur la glycémie du mouton. Ann. Bial. onim. Bioch. Biophys., 13, 753-754.

BAILE C. A., 1968. Régulation of food intake in ruminants. Fed. Proc., 27, 1361-1366.

BAILE C. A., 1971. Metabolites as feedbacks for control of feed intake and receptor sites in goats and sheep. Physiol. Behav., 7, 819-826.

BAILE C. A., FORBES M., 1974. Control of feed intake and regulation of energy balance in ruminants. Physiol. Rev., 54, 160-214.

BAILE C. A., MC LAUGHLIN C. L., 1970. Feed intake of goats during volatile fatty acid injections into four gastric areas. J. Dairy Sci., 53, 1058-1063.

BAILE C. A., MAHONEY A. W., 1966. Hypothalamic fonction in ruminant food intake regulation. In : Regulation of hunger and satiety. Proc. 7th int. Congr. Nutr., Hamburg.

BAILE C. A., MAHONEY A. W., 1967. Hypothalamic fonction in ruminant food intake regulation. 7th int. Congr. Nutr., Hamburg, 2, 67-72.

BAILE C. A., MAHONEY A. W., MAYER J., 1967a. Preliminary report on hypothalamic hyperphagy in ruminants. J. Dairy Sci., 50, 1851-1854.

BAILE C. A., MAHONEY A. W., MAYER J., 1967b. Preliminary report on feeding activity and hypothalamic temperature in goat. J. Dairy Sci., 50, 1854-1857.

BAILE C. A., MARTIN H. F., 1971. Hormones and aminoacids as possible factors in the control of hunger and satiety in sheep. J. Dairy Sci., 54, 897-905.

BAILE C. A., MARTIN H. F., SIMPSON C. W., 1972a. Feeding response to procaine NE isoproterenol and prostaglandins injections into the medial hypothalamus of sheep. Fed. Proc., 31, 397.

BAILE C. A., MARTIN H. F., 1972b. Effect of local anesthesic on taste and feed intake. J. Doiry Sci., 55, 1461-1462.

BAILE C. A., MARTIN H. F., SIMPSON C. W., FORBES J. M., BEYEA J. S., 1974a. Feeding elicited by alpha and beta adrenoceptor agonists injected intrahypothalamically in sheep. J. Dairy Sci., 57, 68-80.

BAILE C. A., MARTIN H. F., FORBES J. M., WEBB R. L., KINGSBURY W., 1974b. Intrahypothalamic injections of prostaglandins and prostaglandin antagonists and feeding in sheep. J. Dairy Sci., 57, $81-88$.

BAILE C. A., MAYER J., 1966. Hyperphagia in ruminants caused by a depressant. Science, 151, 458.

BAILE C. A., MAYER J., 1967. Intragastric injections of liquid diet, water and acetate and meal patterns of goats. Am. J. Physiol., 213, 387-392.

BAILE C. A., MAYER J., 1968a. Effects of intravenous versus intraruminal injections of acetate on feed intake of goats. J. Dairy Sci., 51, 1490-1494.

BAILE C. A., MAYER J., 1968b. Effect of insulin induced hypoglycemia and hypoacetonemia on eating behaviour in goats. J. Dairy Sei., 51, 1495-1499.

BAILE C. A., MAYER J., 1968c. Hypothalamic temperature and the regulation of food intake of goats. Amer. J. Physiol., 214, 677-684. 
BAILE C. A., MAYER J., 1969. Depression of feed intake of goats by metabolites injected meals. Am. J. Physiol., 217, 1830-1836.

BAILE C. A., MAYER J., Mc LAUGHLIN C. L., 1969. Feeding behaviour of goats : ruminal distension, ingesta dilution, and acetate concentration. Am. J. Physiol., 217, 397-402.

BAILE C. A., MAYER J., BAUMGARDT B. R., PETERSON A., 1970. Comparative goldthioglucose effects on goats, sheep, dogs, rats, and mice. J. Dairy Sci., 53, 801-807.

BAILE C. A., PFANDER W. H., 1966. A possible chemosensitive regulatory mechanism of ovine feed intake. Am. J. Physiol., 210, 1243-1248.

BAILE C. A., SIMPSON C. W., KRABILL L. F., MARTIN H. F., 1972. Adrenergic agonists and antagonists and feeding in sheep and cattle. Life Sci., 11, 661-668.

BALCH C. C., 1955. Sleep in ruminants. Nafure, 175, 940-941.

BALCH C. C., CAMPLING R. C., 1962, Regulation of voluntary food intake in ruminants. Nutr. Abstr. Rev., 32, 669-686.

BALDWIN B. A., MEESE G. B., 1977. The ability of sheep for distinguish between conspecifics by means of olfaction. Physiol. Behav., 18, 803-808.

BARGELOH J. F., HIBBS J. W., CONRAD H. R., 1975. Effect of preportal hormone administrations on feed intake and mineral metabolism of cows. J. Doiry Sci., 58, 1701-1707.

BARRETT A. M., 1978. Neuropharmacology of appetite regulation. Proc. Nutr. Soc., 37, $193-199$.

BASSETT J. M., 1963. The influence of cortisol on food intake and glucose metabolism in sheep. J. Endocr., 26, 539-553.

BAUCHOP T., 1979. The rumen anaerobic fungi : colonizers of plant fibre. Ann. Rech. vét., 10, 246-248.

BAUMGARDT B. R., MONTGOMERY M. J., SIMKINS K. L., SUTTIE J. W., 1964. Distension versus chemostatic regulation of food intake in ruminants. J. Dairy Sci., 47, 685.

BELL F. R., 1958. Cité par RUCKEBUSCH Y., 1963.

BELL F. R., ITABISASHI T., 1973. The electroencephalogram of sheep and goats with special reference to rumination. Physiol. Behov., 11, 503-514.

BELL F. R., WEBBER D. E., 1978. The energy content of meals as a determinant of gastric emptying. J. Physiol., 287, 21P.

BENSADOUN A., PALADINES O. L., REID J. T., 1962. Effect of level of intake and physical form of the diet on plasma glucose concentration and VFA absorption in ruminants. J. Dairy Sci., 45, 1203.

BERGEN W. G., 1972. Rumen osmolality as a factor in feed intake control of sheep. J. Anim. Sci., 34, 1054-1060.

BERNARD R. A., 1964. An electrophysiological study of taste reception in peripheral nerves of the calf. Am. J. Physiol., 206, 827-835.

BHATTACHARYA A. N., WARNER R. G., 1967. Rumen $\mathrm{pH}$ as a factor for controlling feed intake in ruminants. J. Dairy Sci., 50, 1116-1119.

BHATTACHARYA A. N., WARNER R. G., 1968a. Effect of propionate and citrate on depressed feed intake after intraruminal infusions of acetate in dairy cattle. J. Dairy Sci., 51, 1091-1094.

BHATTACHARYA A. N., WARNER R. G., 1968b. Influence of varying rumen temperature on central cooling or warming and on regulation of voluntary feed intake in dairy cattle. J. Dairy Sci., 51, 1481-1489.

BINES J. A., SUSUKY S., BALCH C. C., 1969. The quantitative significance of long term regulation of food intake in the cow. Brit. J. Nutr., 23, 695-704.

BINES J. A., 1971. Metabolic and physical control of food intake in ruminants. Proc. Nutr. Soc., 30, $116-$ 122.

BINES J. A., 1976. Cité par WOLTER R., 1978.

BLAXTER K. L., 1950. Energy feeding standards for dairy cattle. Nutr. Abstr. Rev., $20,1$.

BLAXTER K. L., WAINMAN F. W., WILSON R. F., 1961. The regulation of food intake by sheep. Anim. Prod., 3, 51-61.

BLAXTER K. L., 1962. The energy metabolism of ruminants. Hutchinson, London.

BOOTH D. A., 1972. Feeding inhibition by glucose loads compared between normal and diabetic rats. Physiol. Behav., 8, 801-805.

BOST J., 1958a. Sur les phénomènes mécaniques de la rumination. J. Physiol. Paris, 50, $175-179$. BOST J., 1958b. Sur la coordination des actes réflexes de la rumination. J. Physiol. Paris, 50, 180-184.

BOST J., RUCKEBUSCH Y., 1960. Le cardia dans ses rapports avec la rumination. J. Physiol. Paris, 52 , 30-31. 
BOST J., BOIVIN R., RIBOT J., 1969. Effet de la morphine et de l'apomorphine sur le comportement alimentaire chez le jeune agneau. Bull. Soc. Sci. vét. méd. comp. Lyon, 71, 277-282.

BOST J., MC CARTHY L. E., COLBY E. D., BORISON H. L., 1967. Dissociation pharmacologique du comportement alimentaire et de la rumination chez le mouton. $18^{\mathrm{e}}$ Congr. vét. mond., Paris.

BOST J., Mc CARTHY L. E., COLBY E. D., BORISON H. L., 1968. Rumination in sheep : effects of morphine, deslanoside and ablation of area postrema. Physiol. Behav., 3, 877-881.

BROBECK J. R., 1948. Food intake as a mechanism of temperature regulation. Yale J. biol. Med., 70, 545-552.

BRUGĖRE H., 1969. Contribution à l'étude de la physiologie du feuillet (omasum) des ruminants. Th. Doct. vét., Paris.

BRUGĖRE-PICOUX J., BRUGÈRE H., LE BARS H., 1979. Perturbations de la digestion microbienne chez les ruminants : étiologie, pathogénie, éfude clinique, déduction thérapeułique. Rec. Méd. vét., 155, 479-494.

BUENO L., 1975. Rôle de l'acide DL-lactique dans le contrôle de l'ingestion alimentaire chez le mouton. Ann. Rech. vét., 6, 325-336.

BUNNETT N. W., HARRISON F. A., 1979. Endocrine cells in the alimentary tract of the sheep. Ann. Rech. vét., 10, 197-199.

CABANAC M., 1979. Le comportement thermorégulateur. J. Physiol. Paris, 75, 115-178.

CAMPLING R. C., BALCH C. C., 1961. Factors affecting the voluntary intake of food by cows. 1. Preliminary observations on the effect, on the voluntary intake of hay, of changes in the amount of the reticulo-ruminal contents. Brit. J. Nufr., 15, 523-530.

CAMPLING R. C., FREER M., BALCH C. C., 1961. Factors affecting the voluntary intake of food by cows. 2 . The relationship between the voluntary intake of roughages, the amount of digesta in the reticulo-rumen and the rate of disappearance of digesta from the alimentary tract. Brit. J. Nutr., 15, 531-540.

CAMPLING R. C., FREER M., BALCH C. C., 1962. Factors affecting the voluntary intake of food by cows. 3. The effect of urea on the voluntary intake of oat straw. Brit. J. Nutr., 16, 115-124.

CAMPLING R. C., FREER M., 1966. Factors affecting the voluntary intake of food by cows. 8. Experiments with ground, pelleted roughages. Brit. J. Nutr., 20, 229-244.

CHASE L. E., WANGSNESS P. J., MARTIN R. J., 1977. Portal blood insulin and metabolite changes with spontaneous feeding in steers. J. Dairy Sci., 60, 410-415.

CLANCY M., WANGSNESS P. J., BAUMGARDT B. R., 1977. Effect of silage extract on voluntary intake, rumen fluid constituents and rumen motility. J. Dairy Sci., 60, 580-590.

CLARKE D. E., SMOOKLER M. H., HADINATA T., 1972. Acute effects of 6-hydroxy-dopamine and its interactions with dopa on brain amine levels. Life Sci., 3, 97-102.

CONRAD H. R., PRATT A. D., HIBBS J. W., 1964. Regulation of feed intake in dairy cows. 1. Change in importance of physical and physiological factors with increasing digestibility. J. Dairy Sci., 47, 54-62.

CROZE S., BOST J., 1974. Comportement alimentaire du mouton : effets de la nialamide ef de la 6-hydroxy-dopamine. Psychopharmacologia Berlin, 40, 259-268.

DAFNY N., JACOB R. H., JACOBSON E. D., 1975. Gastrointestinal hormones and neural interacfions within the central nervous system. Experientio, 31, 658-660.

DALE E. H., STEWART R. E., BRODY S., 1954. Rumentemperature. 1. Temperature gradients during feeding and fasting. Cornell Vet., 44, 368-374.

DALlaiRE A., TOUTAIN P. L., RUCKEBUSCH Y., 1974. Sur la périodicité du sommeil paradoxal : faits ef hypothèses. Physiol. Bebahv., 13, 395-400.

DEBONS A. F., 1968. G.T.G. damage to the satiety center inhibition in diabetes. Am. J. Physiol., 214, 652-658.

DECAEN C., JOURNET M., 1967. Evolution au début de la lactation, de la sécrétion des principaux acides gras du lait ef de la concentration en acides gras libres du sang chez la vache. Ann. Biol. anim. Bioch. Biophys., 7, 131-143.

DE JONG A., 1979. Regulation of insulin and glucagon secretion in goats. Ann. Rech. vét., 10, 240-243.

DELLA FERA M. A., BAILE C. A., 1979. CCK-octapeptide injected in CSF causes satiety in sheep. Ann. Rech. vét., 10, 234-236.

DEMARQUILLY C., ANDRIEU J., 1970. La valeur alimentaire des foins et des fourrages déshydratés. Rev. Elev., $48^{\mathrm{e}} \mathrm{n}^{\mathrm{O}}$ spéc., 85-97. 
DESWYSEN A., VANBELLE M., FOCANT M., 1978. The effect of silage chop length on the voluntary intake and rumination behaviour of sheep. J. brit. Grassl. Soc., 33, 107-115.

DESWYSEN A., EHRLEIN H. J., 1979. Radiography of intake and (pseudo) rumination behaviour. Ann. Rech. vét., 10, 208-210.

DINIUS D. A., BAUMGARDT B. R., 1970. Regulation of food intake in ruminants. 6. Influence of caloric density of pelleted rations. J. Dairy Sci., 53, 311-316.

DINIUS D. A., KAVANAUGH J. F., BAUMGARDT B. R., 1970. Regulation of food intake in ruminants. 7. Interrelations between food intake and body temperature. J. Dairy Sci., 53, 438-445.

DOCKRAY G. J., 1976. Immunochemical evidence of cholecystokinin-like peptides in brain. Noture, 264, 568-570.

DE VUYST A., ARNOULD R., VANBELLE M., DESWYSEN A., 1974. Effets de l'acétate de sodium sur les fermentations dans le rumen et sur l'appétit. Z. Tierphysiol. Tierernährg. Futtermittelkde, 32, 279-288.

DOWDEN D. R., JACOBSON D. R., 1960. Inhibition of appetite in dairy cattle by certain intermediate metabolites. Nature, 188, 148-149.

DRIVER P. M., FORBES J. M., 1978. Plasma growth hormone and spontaneous meals in sheep. Proc. Nutr. Soc., 37, 100A.

DRIVER P. M., FORBES J. M., SCANES C. G., 1979. Hormones, feeding and temperature in sheep following cerebroventricular injections of neurotransmitters and carbachol. J. Physiol., 290, 399-411.

DULPHY J. P., DEMARQUILLY C., 1972. Influence de la finesse de hachage des ensilages de graminées sur le comportement alimentaire des moutons. Ann. Zootech., 21, 443-449.

DUNCAN D. L., 1953. The effects of vagotomy and splanchnotomy on gastric motility in the sheep. J. Physiol., 119, 157-169.

DUSSARDIER M., 1955. Contrôle nerveux du rythme gastrique des ruminants. J. Physiol. Paris, 47, 170-173.

DUSSARDIER M., 1960. Recherches sur le contrôle bulbaire de la motricité gastrique chez les ruminants. Th. Doct. Sci. nat. Paris.

DUSSARDIER M., ALBE-FESSARD D., 1954. Quelques propriétés du centre vagal contrôlant l'activité réflexe de l'estomac des ruminants. J. Physiol. Paris, 46, 354-357.

EGAN A. R., 1966. Nutritional status and intake regulation in sheep. 5. Effects of intraruminal infusions of VFA upon voluntary intake of roughage by sheep. Austr. J. agric. Res., 17, 741-755.

FOCANT M., GALLOUIN F., 1978. Effets de la perfusion des acides gras volatils sur la prise alimentaire et la rumination chez la chèvre. J. Physiol. Paris, 74, $19 \mathrm{~A}$.

FOCANT M., GALLOUIN F., LECLERCQ M., 1979. Volatile fatty acids and rumination in the goat. Ann. Rech. vét., 10, 226-228.

FOCANT M., 1979. Non publié.

FORBES J. M., BOAZ T. G., 1965. Studies in the roughages and water intake of ewes. Anim. Prod., 7, 289.

FORBES J. M., 1969. The effects of pregnancy and fatness on the volume of rumen contents in the ewe. J. Agric. Sci. Camb., 72, 119-121.

FORBES J. M., 1970. Voluntary food intake of pregnant ewes. J. Anim. Sci., 31, 1222-1227.

FORBES J. M., 1971. Physiological changes affecting voluntary food intake in ruminants. Proc. Nutr. Soc., 30, 135-142.

FORBES J. M., 1972. Effects of estradiol 17 béta on voluntary food intake in sheep and goat. J. Endocrin., $52,8-9$.

FORBES J. M., 1974. Feeding in sheep modified by intraventricular estradiol and progesterone. Physiol. Behov., 12, 741-747.

GERSHON-COHEN J., SHAY H., FELS S. S., 1938. Cités par BELL et WEBBER, 1978.

GIBBS J., YOUNG R. R., SMITH G. P., 1973a. Cholecystokinin decreases food intake in rats. J. comp. physiol. Psychol., 84, 488-495.

GIBBS J., YOUNG R. R., SMITH G. P., 1973b. Cholecystokinin elicits satiety in rats with open gastric fistula. Nafure, 245, 323-325.

GIBBS J., FALASCO J. D., MC HUGH P. R., 1976. Cholecystokinin decreases food intake in rhesus monkeys. Am. J. Physiol., 230, 15-18.

GLICK Z., THOMAS D. W., MAYER J., 1971. Absence of effect of injections of the intestinal hormones secretin and cholecystokinin-pancreozimin upon feeding behaviour. Physiol. Behav., 6, 5-8. 
GOATCHER W. D., CHURCH D. C., 1970. Taste responses in ruminants. 4. Reaction of pigmy goats, normal goats, sheep and cattle to acetic acid and quinine hydrochloride. J. Anim. Sci., 31, 973-981.

GORDON J. G., 1958. The relationship between fineness of grinding of food and rumination. J. Agric. Sci., 51, 78-80.

GRASSÉ P. P., 1955. Traité de zoologie. Tome XVII : Mammifères. Masson, Paris.

GREENHALGH J. F. D., REID G. W., 1967. Separating the effects of digestibility and palatability on food intake in ruminants animals. Nature, 214, 744-745.

GREENHALGH J. F. D., REID G. W., 1971. Relative palatability to sheep of straw, hay and dried grass. Brit. J. Nutr., 26, 107-116.

GROSSMAN S. P., 1962. Direct adrenergic and cholinergic stimulations of hypothalamic mechanisms. Am. J. Physiol., 202, 872-882.

GROVUM W. L., 1979. Factors affecting voluntary food intake by sheep. Ann. Rech. vét., 10, $216-218$.

GROVUM W. L., PHILLIPS G. D., 1978. Factors affecting voluntary intake of food by sheep. 1. Role of distension, flow-rate of digesta and propulsive motility in intestines. Brit. J. Nutr., 40, 323-336.

GROVUM W. L., WILLIAMS V. J., 1977. Rate of passage of digesta in sheep. 6. Effect of level of food intake on mathematical predictions of kinetics of digesta in reficulo-rumen and intestines. Brit. J. Nutr., 38, 425-436.

GUINARD L., 1898. Efude expérimentale de pharmacodynamie comparée sur la morphine ef l'apomorphine. Th. Doct. Méd., Lyon.

HARDING R., LEEK B. F., 1972. Rapidly adapting mechanoreceptors in the reticulo-rumen which also respond to chemicals. J. Physiol., 223, 32P.

HARPER A. B., BENEVENGA N. J., WOLHUETER R. M., 1970. Effects of ingestion of disproportionate amounts of aminoacids. Physiol. Rev., 50, 488-558.

HERBERG L. J., 1960. Hunger reduction produced by injecting glucose in the lateral ventricle of the rat. Nature, 187, 245-246.

HERVEY E., HERVEY G. R., 1966. The relationship between the effects of ovariectomy and progesterone treatement on body weight and composition in female rat. J. Physiol., 187, 44-45.

HETERINGTON A. W., RANSON W. S., 1939. Experimental hypothalamic-hypophysial obesity in rats. Proc. Soc. exp. Biol., 41, 465-466.

HETERINGTON A. W., RANSON W. S., 1942. The spontaneous activity and food infake of rats with hypothalamic lesions. Am. J. Physiol., 136, 609.

HIKOSAKA K., SASAKI Y., TSUDA J., 1979. Effects of glucose, insulin and FFA in food intake in the sheep. Ann. Rech. vét., 10, 237-239.

HOLMES E. G., FRAZER F. J., 1965. An attempt to produce hyperphagia in sheep by electrical damage to the hypothalamus. Austr. J. biol. Sci., 18, 345.

HOUPT T. R., HANCE H. H., 1969. Effect of the 2-deoxy-D-glucose on food intake by the goat, rabbit and dog. Fed. Proc., 28, 648.

HOUPT T. R., 1974. Stimulation of food intake in ruminants by 2-deoxy-D-glucose and insulin. Am. J. Physiol., 227, 161-167.

HOUPT T. R., ANIKA S. M., WOLFF N. C., 1978. Satiety effects of cholecystokinin and caerulein in rabbits. Am. J. Physiol., 235, R 23-R 28.

HUNGATE R. E., 1942. The culfure of diplodinium neglectum, with experiments of the digestion of cellulose. Biol. Bull., 83, 303-319.

HUNGATE R. E., 1943. Further experiments on cellulose digestion by the protozoa in the rumen of cattle. Biol. Bull., 84, 157-163.

HUNGATE R. E., 1966. The rumen and ifs microbes. Acad. Press, New York and London.

HUNT J. N., STUBBS D. F., 1975. The volume and energy content of meals as determinants of gastric emptying. J. Physiol., 245, 209-225.

IGGO A., 1951. Spontaneous and reflexly elicited contractions of reticulum and rumen in decerebrate sheep. J. Physiol., 115, 74-75.

IGGO A., 1955. Tension receptors in the stomach and the urinary bladder. J. Physiol. London, 128, 593-607.

JGGO A., LEEK B. F., 1967a. An electrophysiological study of single vagal efferent units associated with gastric movements in sheep. J. Physiol., 101, 177-204. 
IGGO A., LEEK B. F., 1967b. The afferent innervation of the tongue of the sheep. Symp. Olfaction and Tasie, II. Pergamon, 8, 493-507.

IGGO A., LEEK B. F., 1970. Sensory receptors in the ruminant stomach and their reflex effects, 23-24. In PHILLIPSON A. T., Physiology of digestion and metabolism in the ruminant. 3rd Proc. intern. Symp. Cambridge, England (1969). Oriel Press, Newcastle, England.

INGRAM D. L., WHITTOW G. C., 1962. Effects of variations in respiratory activity and in the skin temperature of the ears on the femperature of the blood in the external jugular vein of the ox (Bos faurus). J. Physiol., 163, 211-221.

JARRIGE R., 1978. Consommation d'aliments et d'eau, 177-206. In Alimentation des ruminants, Ed. INRA, Versailles.

JEAN-BLAIN C., BOIVIN R., BOST J., 1971. Digestibilité et rumination. Effets de la morphine par voie cérébro-ventriculaire chez le mouton. Ann. Nutr. Alim., 25, 121-138.

JOURNET M., HODEN A., 1968. Utilisation des fourrages déshydratés par les vaches laitières. Fourrages, 36, 62.

JOURNET M., REMOND B., 1976. Physiological factors affecting the voluntary intake of feed by cows : a review. Liv. Prod. Sci., 3, 129-146.

KATO S., SASAKI Y., TSUDA T., 1979. Food intake and rumen osmolality in sheep. Ann. Rech. vét., 10, 229-230.

KENNEDY G. C., 1966. Food intake, energy balance and growth. Brit. med. Bull., 22, 216-220.

KNOLL J., 1979. Satietin : a highly potent anorexogenic substance in human serum. Physiol. Behav., 23, 497-502.

KULKOSKY P. J., BRECKENRIDGE C., KRINSKY R., WOODS S. C., 1976. Satiety elicited by the C terminal octapeptide of cholecystokinin-pancreozymin in normal and $\mathrm{VMH}$-lesioned rats. Behav. Biol., 8, 227-234.

LARSSON S., 1954. On the hypothalamic organisation of the nervous mechanism regulating food intake. Acta physiol. scand., 32, Suppl. 115, 1-40.

LE BARS H., GALLOUIN F., 1972. Bases physiologiques du comportement alimentaire. 11e Congr. mond. Zootech. Madrid, 671-702.

LE BARS H., NITESCU R., SIMONNET H., 1953a. Recherches sur la motricité du rumen chez les petits ruminants. 1. Motricité normale. Bull. Acad. vét., 26, 287-300.

LE BARS H., NITESCU R., SIMONNET H., 1953b. Recherches sur la motricité du rumen chez les petits ruminants. 2. Relation entre la motricité et la glycémie. Bull. Acad. vét., 26, 351-359.

LE BARS H., LEBRUMENT M., NITESCU R., SIMONNET H., 1954. Recherches sur la motricité du rumen chez les petits ruminants. 4. Action de l'injection intraveineuse d'acides gras à courte chaîne. Bull. Acad. vét., 27, 53-67.

LEIBOWITZ S., 1970a. A hypothalamic beta adrenergic satiety system antagonises an alpha adrenergic hunger system in the rat. Noture, 226, 963-964.

LEIBOWITZ S., 1970b. Reciproqual hunger-regulating circuits involving alpha and beta receptors located respectively in the ventromedial and lateral hypothalamus. Proc. not. Acad. Sci., 67, 1063-1070.

LEIBOWITZ S., 1971. Hypothalamic alpha and beta adrenergic systems regulate both thirst and hunger in the rat. Proc. nat. Acad. Sci., 68, 332-334.

LE MAGNEN J., 1952. Les phénomènes olfacto sexuels chez le rat blanc. Arch. Sci. physiol., 6, 295-331.

LE MAGNEN J., 1969. Peripheral and systemic actions of food in the caloric regulation of intake. Ann. N. Y. Acad. Sci., 157, 1126-1157.

LE MAGNEN J., 1976. Mécanismes physiologiques de la prise alimentaire ef régulation du bilan d'énergie chez l'homme. Ann. Nutr. Alim., 30, 315-330.

LE MAGNEN J., TALLON S., 1967. Effet des administrations d'insuline ef de thryoxine sur la fréquence et l'amplitude unitaire des prises d'aliment chez le rat. C. R. Soc. Biol., 161, 1303-1306.

LINDSAY D. R., 1965. The importance of olfactory stimuli in the mating behaviour of the ram. Anim. Behav., 13, 75-78.

LITTLE J. A., HAWKINS G. E., 1963. Relationship between acetic and propionic acid content of blood and feed intake in young dairy animals. J. Dairy Sci., 46, 634.

LOUVIER J. A., COLVIN H. W., ISHIZAKI G., IWAMOTO G. A., PARKER H. R., 1979. Effect of rumen insufflation on ruminal contraction rate in sheep. J. Anim. Sci., 48, 934-940.

MANNING R., ALEXANDER G. I., KRUEGER H. M., BOGART R., 1959. The effect of intravenous glucose injections on appetite in adult ewes. Am. J. Vet. Res., 20, 242-246. 
MANNS J. G., BODA J. M., 1967. Insulin release by acetate, propionate, butyrate and glucose in lambs and adult sheep. Amer. J. Physiol., 212, 747.

MAYER J., 1955. Regulation of energy intake and the body weight : the glucostatic theory and the lipostatic hypothesis. Ann. N. Y. Acad. Sci., 63, 15-43.

MAYER J., FRENCH R. G., ZIGHERA C. Y., BARNETT R. G., 1955. Hypothalamic obesity in the mouse. Am. J. Physiol., 182, 75.

MC HUGH P. R., MORAN T. H., 1979. Calories and gastric emptying : a regulatory capacity with implications for feeding. Am. J. Physiol., 236, R 254-R 260.

MENDEL V. E., RAGHAVAN G. V., 1964. A study of diurnal temperature patterns in sheep. J. Physiol., 174, 206-216.

MONTGOMERY M. J., SCHULTZ L. H., BAUMGARDT B. R., 1963. Effect of intraruminal infusion of volatile fatty acids and lactic acid on voluntary hay intake. J. Dairy Sci., 46, 1380-1384.

MONTGOMERY M. J., BAUMGARDT B. R., 1965. Regulation of food intake in ruminants. a) Pelleted rations varying in energy concentration. J. Dairy Sci., 48, 569-574.

MORGAN D. J., L'ESTRANGE J. L., 1977. Voluntary feed infake and metabolism of sheep when lactic acid is administered in the feed or intraruminally. J. brit. Grassl. Soc., 32, 217-224.

MUNRO J., 1957. Sleep in sheep. Proc. brit. Soc. Anim. Prod., 71-75.

MURDOCH J. C., 1965. The effect of length of silage on its voluntary intake by cattle. J. brit. Grassl. Soc., 20, 54-58.

NICHOLSON T., 1979. Some effects of insulin on eating and rumination. Ann. Rech. vét., 10, 231-233.

PAPAS A., HATFIELD E. E., 1978. Effects of oral and abomasal administration of V.F.A. on voluntary feed intake of growing lambs. J. Anim. Sci., 46, 288.

PETERSON A. D., BAUMGARDT B. R., BAILE C. A., 1971. Feeding induced in the bovine by infusion of the cerebral ventricular system with pentobarbital or glucose. Fed. Proc., $30,568$.

PETERSON A. D., BAILE C. A., BAUMGARDT B. R., 1972. Cerebral ventricular injections of pentobarbital, glucose and sodium chloride into sheep and calves, and feeding. J. Dairy Sci., 55, 822-828.

PHILLIPSON A. T., ASH R. W., 1965. Physiological mechanisms affecting the flow of digesta in ruminants, 97-107. In DOUGHERTY R. W., Physiology of digestion in the ruminant. Butterworths, Washington D.C.

REHFELD J. F., KRUSE-LARSEN C., 1978. Gastrin and cholecystokinin in human cerebrospinal fluid. Immunochemical determination of concentrations and molecular heterogeneity. Brain Research, 155, 19-26.

REID C. S. W., JOHN A., ULYATT M. J., WAGHORN G. C., MILLIGAN L. P., 1979. Chewing and the physical breakdown of feed in sheep. Ann. Rech. vét., 10, 205-207.

ROBINSON G. A., BUTCHER R. W., SUTHERLAND E. W., 1970. On the relation of hormones receptors to adenylcyclase. In DANIELLI J. F., Fundamental concepts in drugs-receptors interaction. Acad. Press N. Y.

ROOK J. A. F., BALCH C. C., CAMPLING R. C., 1960. The effects of intraruminal infusions of acetic, propionic and butyric acids on nitrogen retention in growing heifers. Proc. Nutr. Soc., 19, i-ii.

ROSS J. P., KITTS W. D., 1973. Relationship between postprandial plasma volatile fatty acids, glucose and insulin levels in sheep fed different feeds. J. Nutr., 103, 488-493.

RUCKEBUSCH Y., 1963. Recherches sur la régulation centrale du comportement alimentaire chez les ruminants. Th. Doct. Sci. nat., Lyon.

RUCKEBUSCH Y., 1967. Etude polygraphique des variations spontanées ou provoquées du comportement alimentaire chez les petits ruminants. Arch. Sci. physiol., 21, 449-473.

RUCKEBUSCH Y., 1968. Acquisitions récentes en physiologie digestive chez les ruminants. Cah. Méd. vét., 27, 111-126.

RUCKEBUSCH Y., 1975. Feeding and sleep patterns of cows prior to and post parturition. Applied Anim. Ethol., 1, 283-292.

RUCKEBUSCH Y., BELL F., 1970. Etude polygraphique et comportementale des états de veille ef de sommeil chez la vache (Bos taurus). Ann. Rech. vét., 1, 41-62.

RUCKEBUSCH Y., BUENO L., 1972. Analyse quantitative des relations activité alimentaire-étal de vigilance chez les bovins en stabulation. Ann. Rech. vét., 3, 399-420.

RUCKEBUSCH Y., DOUGHERTY R. W., COOK H. M., 1974. Jaw movements and rumen motility as criteria for measurement of deep sleep in cattle. Amer. J. vet. Res., 35, 1309-1312. 
RUCKEBUSCH Y., FARGEAS J., DUMAS J. P., 1970. Recherches sur le comportement alimentaire des ruminants. 9. La masticafion mérycique. Rev. Méd. vét., 121, 345-357.

RUCKEBUSCH Y., GAUJOUX M., 1976. Sleep inducing effect of a high protein diet in sheep. Physiol. Behav., 17, 9-12.

RUCKEBUSCH Y., LAPLACE J. P., 1968. Modifications pharmacologiques du comportement alimentaire : prise de nourriture ef rumination chez le mouton. Psychopharmacologia, 12, 104-114.

RUCKEBUSCH Y., MARQUET J. P., 1965. Effets comportementaux de l'ablation du rumen chez les ovins. C. R. Soc. Biol., 159, 394.

RUSSEK M., 1970. Demonstration of the influence of an hepatic glucosensitive mechanism on food intake. Physiol. Behav., 5, 1207-1209.

RUSSEK M., 1971. Hepatic receptors and the neurophysiological mechanisms controlling feeding behaviour, 214-232. In EHRENPREIS S., Neuroscience Research, 4, Acad. Press, N. Y.

SCHAMBYE, 1951. Volatile acids and glucose in portal blood of sheep. Nord vet. Med., 3, 355-370.

SCHARRER E., BAILE C. A., MAYER J., 1970. Effect of aminoacids and protein on food intake of hyperphagic and recovered aphagic rats. Am. J. Physiol., 218, 400-404.

SENEL S. H., OWEN F. G., 1966. Relation of dietary acetate and lactates to dry matter intake and volatile fatty acid metabolism. J. Dairy Sci., 49, 1075.

SEOANE J. R., BAILE C. A., 1972. Effect of intraventricular (3rd ventricle) injections of 2-deoxy-Dglucose, glucose and xylose on feeding behaviour of sheep. Physiol. Behav., 9, 423-428.

SEOANE J. R., BAILE C. A., 1973. lonic changes in cerebrospinal fluid and feeding, drinking and temperature of sheep. Physiol. Behav., 10, 915-923.

SEOANE J. R., BAILE C. A., MARTIN F. H., 1972. Humoral factors modifying feeding behaviour of sheep. Physiol. Behav., 8, 993-995.

SEOANE J. R., BAILE C. A., WEBB R. L., 1973. Feeding behaviour in sheep as related to the hypnotic activities of barbiturates injected into the third ventricle. Pharmacol. bioch. Behav., 1, 47-53.

SHALK A. F., AMADON R. S., 1928. Physiology of the ruminant stomach (bovine). Study of the dynamic factors. Bull. agr. exp. Stat. North Dakota, $\mathrm{n}$ 216, 1-63.

SIMKINS K. L., SUTTIE J. W., BAUMGARDT B. R., 1965a. Regulation of food intake in ruminants. 3. Variation in blood and rumen metabolites in relation to food intake. J. Dairy Sci., 48, 16291634.

SIMKINS K. L., SUTTIE J. W., BAUMGARDT B. R., 1965b. Regulation of food intake in ruminants. 4. Effect of acetate, propionate, butyrate, and glucose on voluntary food intake in dairy cattle. J. Dairy Sci., 48, 1635-1642.

SMITH G. P., EPSTEIN A. N., 1969. Increased feeding in response to decreased glucose utilisation in the rat and monkey. Am. J. Physiol., 217, 1083-1087.

SMITH C. J. V., 1972. Hypothalamic glucose receptors. The influence of goldthioglucose implants in the ventromedial and lateral hypothalamic areas of normal and diabetic rats. Physiol. Behov., 9, 391.

SMITH C. M., KRISHNAMURTI C. R., KITTS W. D., 1979. Effect of lactic acid administration on rumen myoelectrical activity and pressure changes in the sheep. Can. J. Anim. Sci., 59, 255-264.

SNAPIR N., GLICK Z., 1978. Cholecystokinin and meal size in the domestic fowl. Physiol. Behav., 21, $1051-1059$.

SOULAIRAC A., 1962. The adrenergic and cholinergic control of food and water intake. Ann. Acad. SCi. N. Y., 157, 934-961.

SOULAIRAC A., 1958. Les régulations psychophysiologiques de la faim. J. Physiol. Paris, 50, 663-783.

SPURLOCK G. M., CLEGG M. T., 1962. Effect of cortisone acetate on carcass composition and wool characteristics of weaned lambs. J. Anim. Sci., 21, 494-500.

THEURER B., WOODS W., POLEY G. E., 1966. Comparison of portal and jugular blood plasma aminoacids in lambs at various intervals postprandial. J. Anim. Sci., 25, 175-180.

TINDAL J. S., KNAGGS G. S., HART I. C., BLAKE L. A., 1978. Release of growth hormone in lactating goats in relation to behaviour, stages of sleep, electroencephalograms, environmental stimuli and levels of prolactin, insulin, glucose and free fatty acids in the circulation. J. Endocr., 76, 333-346.

TITCHEN D. A., 1953. Reflex contractions of the reticulum. J. Physiol., 122, 32.

ULYATT M. J., 1965. The effects of intraruminal infusions of volatile fatty acids on food intake of sheep. N. Z. J. agr. Res., 8, 397-408. 
UNGERSTEDT U., 1971a. Stereotaxic mapping of the monoamine pathways in the rat brain. Acta physiol. scand., 82, suppl. 367, 1-48.

UNGERSTEDT U., 1971b. Adipsia and aphagia after 6-hydroxydopamine induced degeneration of the nigrostriatal dopamine system. Acta physiol. scand., 82, suppl. 367, 95-122.

VAN DER GUGTEN J., SLANGEN J. L., 1977. Release of endogenous catecholamines from rat hypothalamus in vivo related to feeding and other behaviours. Pharm. Bioch. Behav., 7, 211-219.

VAN MIERT A. S. J. P. A. M., 1971. Inhibition of gastric motility by endotoxin (bacterial lipopolysaccharide) in conscious goats and modification of this response by splanchnectomy, adrenalectomy or adrenergic blocking agents. Arch. int. Pharmacodyn., 193, 404-415.

WADE G. N., 1972. Gonadal hormones and behavioral regulation of body weight. Physiol. Behav., 8, 523-534.

WADE G. N., ZUCKER G. R., 1970. Development of hormonal control over food intake and body weight in female rats. J. comp. physiol. Psychol., 70, 213-220.

WESTRA R., CHRISTOPHERSON R. J., 1976. Effects of cold on digestibility, retention time of digesta, reticulum motility and thyroid hormones in sheep. Can. J. Anim. Sci., 56, 699-708.

WOLTER R., 1978. La régulation de la consommation volontaire chez la vache laitière. Rev. Méd. vét., 124, 837-862.

WYRWICKA W., DOBREZCKA C., 1960. Relationship between feeding and satiation centers of the hypothalamus. Seience, 132, 805-806. 